\title{
"No hay término ni fin en hacer ni multiplicar los libros": Las casas de impresores y la diversificación de la cultura libresca durante el siglo XVII en la capital novohispana
}

\author{
Ariel Antonio Morán Reyes ${ }^{1}$
}

Recibido: 30 de enero de 2018 / Aceptado: 30 de junio de 2018

Resumen. En este artículo se documenta el desarrollo y evolución de las imprentas emplazadas en el cuadro central de la Ciudad de México durante en el siglo XVII. Además, se consigna la ubicación de los locales de los más de treinta impresores que se establecieron en esta centuria en la capital novohispana, y se establece un análisis histórico-espacial que permite determinar, de manera dinámica, el ambiente y posibles influencias entre las casas de impresión en estos años. Algunas de las relaciones entre los impresores se derivaron de una localización cercana, pero también por sus nexos laborales, comerciales y familiares, por lo que cada uno de ellos estuvo vinculado con los otros, directa o indirectamente. Esto permite apreciar algunos casos concretos que han sido olvidados, por lo que traerlos a la memoria es recrear una serie de relaciones vivenciales sobre la imprenta y la historia del libro del siglo XVII y su conexión con la Ciudad de México actual. La intención es ahondar en las casas de impresión, y no sólo en una serie de referentes descriptivos. Si bien el periodo diecisietesco se destacó por ser un periodo de ínclitos bibliófilos y de bibliotecas insignes, otras de sus características en materia de impresos fueron: la conformación de dinastías de impresores encabezadas muchas veces por las viudas, la alternancia de actividades entre la impresión y la venta de libros, el incremento del número de impresores (muchos de ellos fugaces) en ésta y otras ciudades, y la diversificación de diseños y materiales para imprimir.

Palabras clave: Impresores y libreros; impresos mexicanos; mujeres impresoras; historia del libro; Ciudad de México en el siglo XVII.

\section{[en] "There's no limit or end to making or multiplying books": Printing houses and the diversification of book culture in the 17th century in the capital of New Spain}

\begin{abstract}
This article documents the development and evolution of the printing presses situated in the central core of the City of Mexico in the 17th century. In addition, the locations of the more than thirty printing presses established in the 17 th century are provided, and a spatial-historical analysis is implemented, which allows for a dynamic determination of the ambience and the possible influence of the printing houses of the time. The relationships between some of the printers were derived from their proximity, but also from commercial, familiar and work-related ties; thus, each printer was directly or indirectly linked to the others. This allows for the appreciation of specific cases that have been forgotten; and reviving their memory means recreating a series of experiential relations regarding the press and the history of books in the 18th century, and their connection with Mexico City today. The intent is to delve into the printing houses, and not only into a series of descriptive referents. Although the 17 th century stood out as a period of illustrious bibliophiles and notable libraries, it also shared
\end{abstract}

1 Universidad Nacional Autónoma de México (UNAM), Facultad de Filosofía y Letras.

E-mail: a.moran@comunidad.unam.mx 
other characteristics in relation to printing: the formation of printing dynasties which were often lead by widows, the alternation of printing and bookselling activities, the growth in the quantity of printers (many of which were short-lived) in this city and others, and the diversification of printing designs and materials.

Keywords: Printers; Booksellers; Mexican printed matter; Women printers; History of Books; Mexico City in the $17^{\text {th }}$ century.

Sumario. 1. Preámbulo. 2. Las casas de impresión y el auge libresco en la Ciudad de México durante el siglo XVII. 3. Ubicación física de cada uno de los talleres y casas de impresión. 4. Conclusiones. 5. Referencias bibliográficas.

Cómo citar: Morán Reyes, A. A. (2019) "No hay término ni fin en hacer ni multiplicar los libros": Las casas de impresores y la diversificación de la cultura libresca durante el siglo XVII en la capital novohispana, en Revista Complutense de Historia de América 45, 159-187.

No sé si es más veloz en idear y formar un libro que en olvidarlo. Encomiéndalo cuando mucho, a la gaveta de un escritorio, y éste le parece bastante premio de su trabajo. Dichoso puede llamarse el papel suyo que esto consigue ${ }^{2}$.

Carlos de Sigüenza y Góngora

\section{Preámbulo}

El enunciado entrecomillado que intitula este trabajo -y que ayuda a introducirse en él- es la misma frase que utilizó el poeta barroco Bernardo de Balbuena en la nota introductoria dirigida al lector, en la edición príncipe de 1604 de su Grandeza mexicana, a saber: "faciendi plures libros non est finis"3. Con esta máxima latina (tomada del Capítulo 12 del Eclesiastés) se puede dar una idea de la diversidad del libro en la Nueva España, pero con especial énfasis en la Ciudad de México, durante las postrimerías del siglo XVI y los inicios del XVII (época en la que compuso su obra el otrora capellán en Guadalajara): ya sea en cuanto a las ediciones de libros, de sus elementos materiales y fuentes tipográficas, pero también de temas, estilos y profusidad de las obras escritas. Así, en los siguientes años, "la ciudad de México, sede de la primera imprenta en América, siguió con auge manifiesto imprimiendo y multiplicando talleres"4.

Cabe mencionar que la grandeza a la que aludió Balbuena se circunscribía a una evocación de la nobilísima capital como ciudad letrada y suntuaria (con la Universidad y los colegios, los arcos de triunfo en entradas públicas, el oficio de las artes), como puede apreciarse en los tercetos del capítulo IV de su poema corográfico, en el cual encomia a las "letras, virtudes, variedad de oficios"s. Resalta la mención que hace a las ars mechanica, como la pintura y la escultura ("El pincel y escultura que arrebata | El alma y pensamiento por los ojos"), pero de igual manera al oficio del

\footnotetext{
Sigüenza y Góngora, 1959: 14.

3 Balbuena, 1927: 3. La mayoría de las versiones de la Vulgata, asientan esta frase como: "faciendi plures libros nullus est finis".

4 Pompa y Pompa, 1988: 22.

$5 \quad$ Balbuena, 1927: 78.
} 
impresor: "De abiertos moldes una y otra imprenta | Bello artificio que el humano cursó | Del mundo o en inmortal vida sustenta"6. Precisamente, esta inmortalidad soportada en la materialidad del libro es a lo que se abocan sustancialmente las investigaciones patrimonialistas y sobre la memoria.

La relevancia de reconstruir al libro antiguo, histórica y culturalmente, a través de su materialidad y relaciones documentales, refiere a complejos fenómenos sociales en los cuales se realizan valoraciones de diversa índole sobre el pasado, y esto se explica a través de lo que Ricœur denominó la "prueba documental", que implica su reconstitución a partir de diversos elementos, que van más allá del plano textual primario. La tradición europea permeó en la mayoría de los quehaceres letrados en la Nueva España. A través de "los colegios, la imprenta establecida en 1539, la Universidad en 1551 y las numerosas bibliotecas y casas de estudio fundadas por todo el país, penetró la cultura europea que se enseñó a través de las varias lenguas en uso, de las que se formaron gramáticas, vocabularios y cartillas, reveladores de un alto sentido pedagógico-cultural"8. Para realizar una investigación sobre esta cultura libresca, bien puede hacerse a partir de "estructura material" de los impresos, o desde su "estructura formal", y cada una implica una esquematización de elementos que deben ser tomados en cuenta. Según lo establecido por Immanuel Kant, el filósofo de Königsberg: "un libro es un escrito (ya hecho con una pluma, ya con caracteres de imprenta, con pocas o muchas hojas, lo cual aquí no importa nada) que representa un discurso dirigido al público por medio de los signos visibles del lenguaje. El que habla al público en su propio nombre es el autor. El que en un escrito habla al público en nombre de otro (de un autor) es el editor". Si bien Kant reconoce que existe una parte material en el libro, reconoce otra inmaterial, ambas intelectivas, que coadyuvan a potenciar el uso público de la razón: "un libro se compone en parte de un producto del arte; producto mecánico (opus mechanicum) que puede llevarse a cabo por todo poseedor legítimo de un ejemplar del libro [...] Pero el libro se compone en parte del simple discurso del autor al público, discurso que no puede ser reproducido públicamente (proestatio operce) por un tercero, sin asentimiento del autor [...] el error consiste en confundir estas dos cosas".

Lo anterior conmina a reconocer la importancia que tiene la reedificación de esa memoria impregnada en los elementos materiales, textuales, y también visuales, de los documentos de la época colonial -específicamente de la capital novohispana, que es el asunto que modestamente nos ocupa-. Como contribución a una parte de los estudios de la memoria impresa, el objetivo general de este trabajo es ilustrar y documentar el desarrollo y evolución (ubicación, conformación y presencia) de las imprentas enclavadas en el cuadro central de la capital mexicana en el siglo XVII. En este trabajo se establecerá un análisis histórico-espacial que permita consignar la ubicación de los locales de los treinta y dos casos de impresores que se establecieron en este marco temporal, pero además determinar, de manera dinámica, el ambiente y posibles influencias en cada una de las casas de impresión en esa centuria. Este tipo de análisis consiste en espacializar y determinar una ubicación a partir del mapeo en un cierto periodo, cuya finalidad es conocer y explorar las prácticas sociales

Ibídem: 79-80.

Ricœur, 2004: 231.

$8 \quad$ Torre Villar, 1974: 171. Aunque fue fundada por una Real Cédula en 1551, la Real y Pontificia Universidad de México se inauguró hasta 1553.

9 Kant, 1873: 132-133. 
que han definido un entorno urbano específico, a raíz de algunos acontecimientos o revoluciones culturales ${ }^{10}$. Si bien se pueden mencionar algunos casos en los que la presencia de los ejecutores de estas "industrias de la inteligencia"11 (como la labor del impresor) propulsó el desarrollo de su entorno urbano ${ }^{12}$, debe señalarse que esto no es algo privativo de esta actividad, ni mucho menos de la Ciudad de México, ya que las ciudades novohispanas medianas fueron fundadas cada una con una función social específica. La ciudad de Puebla se desarrolló a partir de la organización gremial de la industria textil (con talleres y tiendas); la zona del Bajío por su orden social de tipo comunal en torno a la agricultura, pero también a las redes comerciales fundadas gracias a nexos familiares en el ramo del curtido del cuero. Lo mismo puede señalarse de las regiones mineras septentrionales ${ }^{13}$.

En este sentido, algunas de las relaciones entre los impresores se derivaron de una localización cercana (a algunas calles de distancia), por vínculos laborales (algunos cajistas y oficiales de imprenta colaboraron hasta con cinco diferentes impresores), comerciales (entre libreros e impresores) o, incluso, nexos familiares (y la subsecuente conformación de linajes de herederos y nuevas casas de impresión). Esto permite apreciar algunos casos concretos y muy particulares que han sido desatendidos por la historia documental general, por lo que traerlos a la memoria es bosquejar algunas ilaciones complejas de la cultura impresa del siglo XVII, en relación con la Ciudad de México del presente. La intención es ahondar en las contingencias de los talleres de impresión.

Para segmentar el trabajo, se realizó una asignación razonada, de acuerdo a las relaciones directas e indirectas entre todos los impresores de esta centuria. Conviene acotar que el español Diego Fernández de León no fue omitido de esta investigación, pese a que algunos autores excluyen su trabajo de este siglo y lo sitúan de lleno en el XVIII. Ciertamente, en un primer periodo, su imprenta se localizó en Puebla de los Ángeles (a partir de 1683), y luego introdujo la maquinaria para imprimir en Oaxaca en 1685 (aunque ésta se traspasó y fue utilizada hasta 1720). También conviene mencionar que se dedicó primero a la mercadería de libros. No obstante, en 1690 trasladó a su hijo a la Ciudad de México para la regentía de una imprenta en la Casa Profesa, acompañado por el prensista español Juan Manuel de Castañeda. Por esta razón, no escapa del espectro de estudio de este trabajo.

\section{Las casas de impresión y el auge libresco en la Ciudad de México durante el siglo XVII}

La mencionada obra de Bernardo de Balbuena, la Grandeza mexicana, fue impresa en la Ciudad de México por Melchor Ocharte, vástago de María de Sançoric, segunda esposa y heredera del célebre Pedro Ocharte (Pierre Ochart), uno de los seis impresores con licencia que hubo en la Nueva España durante el siglo XVI, socio, además, de Antonio Ricardo, quien fuera introductor de la imprenta en Lima. Este caso particular muestra la urdimbre de relaciones (comerciales, familiares y

\footnotetext{
Borah, 1974: 71-76.

Barbosa, 1981: 34 .

Febvre - Martin, 2005: 383.

Moreno, 1974: 96-105 y 117-126.
} 
zonales) que constituirían la tendencia de la historia de los impresos mexicanos en los siguientes años. Melchor y su medio hermano, Luis, fueron ambos impresores herederos, y su historia sirve muy bien, para efectos de este trabajo, como ejemplo de algunas de las principales características y rasgos bibliológicos del siglo XVII en materia de impresión.

Esta centuria se destacó, entre otras cosas, por ser un periodo de ínclitos bibliófilos (basta simplemente revisar el aciago caso de Melchor Pérez de Soto) ${ }^{14}$, pero también de grandes e insignes bibliotecas ${ }^{15}$ : "las bibliotecas se hacen más copiosas en el siglo XVII. Sobresalen entre ellas las de los conventos, universidades y colegios, pero las hubo también muy notables de individuos particulares. Recuérdense las de Sigüenza y Góngora y de sor Juana Inés de la Cruz" ${ }^{16}$. Asimismo, en este siglo comenzaron a gestarse muchas dinastías de impresores, algunas de las cuales se fortalecieron y otras languidecieron tras el curso de las generaciones (como la de los Ocharte). Ahora bien, salvo ciertas menciones, los sucesores o herederos quizá no destacaron de la misma manera que los precursores del siglo XVI, como ocurrió con Luis Ocharte, hijo de Pedro Ocharte y María Figueroa, su primera mujer (de quien enviudó) -a su vez hija de Juan Pablos (Giovanni Paoli)-, quien pese a su estirpe no consiguió hacerse de un taller propio. Los descendientes de Ocharte no alcanzaron la prosapia de éste, ni por su administración ni por el gusto en sus diseños, tanto en el de la composición como en el uso de grabados (hay que recordar que, inclusive, Antonio de Espinosa y Pedro Balli trabajaron para él).

Sin embargo, en algunos casos, los herederos lograron entramar relaciones con otras familias del mismo rubro, y erigir así verdaderos linajes en materia de impresión, pero asimismo de locales y puntos de venta. En otras palabras, pese a que en este siglo pulularon muchos "impresores menores" y poco relevantes -en palabras de Ernesto de la Torre Villar- ${ }^{17}$, algunos de ellos cumplieron el papel de diversificar el negocio familiar de la sola actividad de imprimir hacia el comercio de libros (o viceversa), ya fuera que tuvieran en el mismo local de la imprenta su tienda, como Agustín de Santiesteban y Vértiz en sociedad con Francisco Rodríguez Lupercio, o Juan José Guillena Carrascoso (Figura 1), o que tuvieran la prensa en un punto y la librería en otro no muy distante, o simplemente que la traspasaran (como ocurrió con la viuda del mismo Garrido, que vendió la imprenta a Diego Gutiérrez, y que ya antes había trasladado la tienda de la Calle Tacuba a la Calle de la Acequia, para luego venderle los impresos al librero Francisco Clarín, quien se estableció en la Calle de San Francisco) ${ }^{18}$. En el siglo XVI, algunos impresores comenzaron siendo tipógrafos de otro impresor propietario; otros lo hicieron como mercaderes de libros y después se pasaron a la labor de imprimirlos (como el propio Balli u Ocharte), renunciando a su antiguo oficio, pero rara vez de forma simultánea. En el siglo XVII muchos dueños de talleres se diversificaron, ya que eran impresores y al mismo los

14 Leonard, 1976: 131-149; Anderson, 1997: 87.

15 Gracias al inventario de 1862 del médico y bibliotecario José María Benítez - para la conformación de la Biblioteca Nacional de México en 1867- se puede estimar el volumen de las colecciones de muchas bibliotecas conventuales novohispanas; Informe sobre la Biblioteca Nacional México, 1862. Biblioteca Nacional [México] (en adelante BNM), Colección Lafragua, leg. 119, f. 4v. Además, se pueden revisar estudios recientes como el de Carreño, 2013: 119-271.

16 Gómez, 1981-1982: 67.

17 Torre Villar, 2009: 149.

18 Instalación de la librería de la mercader Ana de Herrera en la calle de Azequia. México, 10-IX-1626. Archivo General de la Nación [México] (en adelante AGNM), Reales Cédulas Duplicados, leg. 8, exp. 359, f. 454. 
expendían ( $\sin$ prescindir de uno u otro oficio), y al acrecentarse las familias esto se hizo más conducente. Aunque Bernardo Calderón comenzó como librero y luego se hizo impresor, nunca abandonó su primera ocupación, y dejó a sus herederos ambos locales.

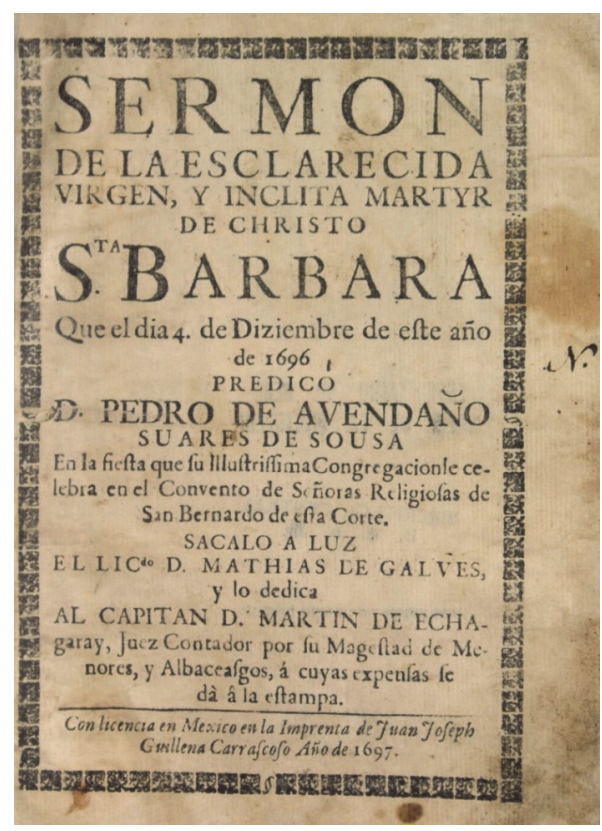

Figura 1. Portada del Sermon de la esclarecida Virgen, y inclita Martyr de Christo S. ${ }^{\text {ta }}$ Barbara, del predicador jesuita Pedro de Avendaño Suárez de Souza, impreso en 1697 por Juan José Guillena Carrascoso ${ }^{19}$.

A este respecto, un lugar destacado en el mundo de la imprenta novohispana, lo ocuparon las viudas, quienes se hicieron cargo de las empresas heredadas por sus cónyuges, algunas con gran éxito y otras con ciertas avenencias para expenderlas. Como lo señaló Manuel Carrera Stampa, al morir el impresor, su oficial pocas veces podía optar para quedarse con el taller (salvo que se hubiera convertido en su yerno), dado que, con su fallecimiento, se suscitaba "la ineludible y forzosa terminación del negocio". Ahora bien, existen casos en los que el oficial llegó a un acuerdo con la viuda para adquirir el taller (como fue el caso de Diego Gutiérrez) o continuar en la imprenta si la nueva dueña optaba por seguir con el establecimiento, para lo cual se tenía que estatuir otro tipo de convenio. En otros casos, el taller era traspasado a otro maestro impresor.

Si no se presentaba la muerte súbita del maestro impresor, lo esperado "era que el oficio se heredase de padres a hijos, y por tanto, los secretos profesionales del maestro los heredase el hijo"20, empero, lo que ocurría casi en la mayoría de los ca-

9 Fondo Antiguo de la Biblioteca Central, de la UNAM (sig. BX4700.B15 A84).

20 Carrera, 1954: 56. 
sos era que "la mujer continuaba con la tienda y taller de su marido difunto, con los mismos aprendices y oficiales a su servicio. La historia de la imprenta en México nos da un claro ejemplo de ello"21. Esto se explica gracias a que estas mujeres no sólo se desposaron con prensistas, sino que, algunas, fueron también hijas de impresores ${ }^{22}$. Entre las viudas puede mencionarse a María de Espinosa, esposa de Diego López Dávalos (hija del conocido impresor español del XVI, Antonio de Espinosa, que fuera en un inicio tipógrafo de Juan Pablos); Catalina del Valle, la viuda de Pedro Balli (Pierre Vailly) -quien fungiera como intérprete de lengua francesa ante el tribunal de la Inquisición-; Ana de Herrera, viuda de Diego Garrido; Paula de Benavides, viuda de Bernardo Calderón, y su hija, María de Benavides, viuda de Juan de Ribera (Figura 2); Jerónima Delgado, la de Francisco Rodríguez Lupercio, y la mencionada segunda esposa de Pedro Ocharte. La viuda de Diego Fernández de León, Ángela Ruiz Machorro (de la familia Ruiz, herederos de Henrico Martínez), continuó con la labor de imprimir, pero ya en el siglo XVIII. En este mismo siglo trabajaron e imprimieron Juan José Guillena Carrascoso y su esposa, María de San José Contreras y Monroy, aunque ésta murió antes que él (como ocurrió con la primera esposa de Pedro Ocharte, María de Figueroa, hija de Juan Pablos).

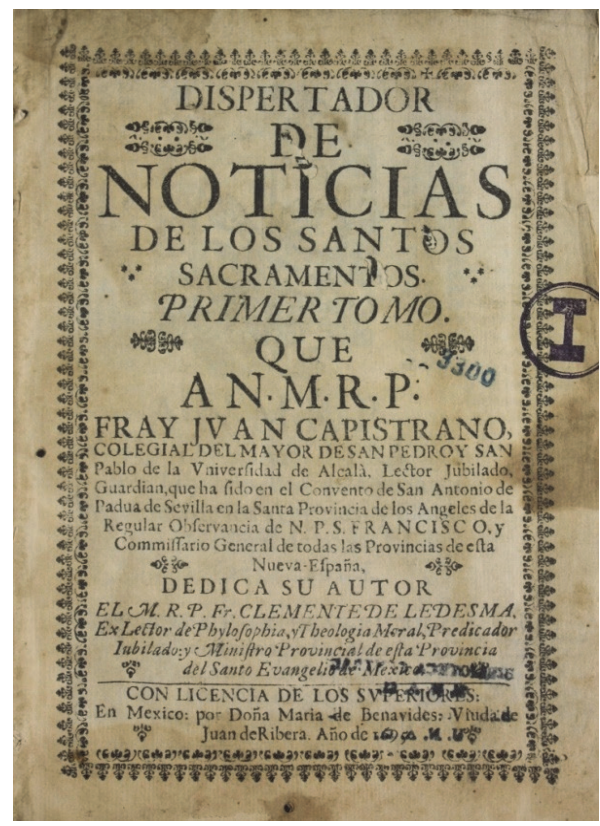

Figura 2. Portada del primer tomo del Dispertador de noticias de los Santos Sacramentos, del franciscano Clemente de Ledesma, impreso en 1695 por María de Benavides ${ }^{23}$.

\footnotetext{
Ibídem: 35 .

Garone, 2010: 185-190.

Fondo Antiguo de la Biblioteca Central, de la UNAM (sig. BX2200.L45).
} 
El periodo de trabajo como impresora de Paula de Benavides comenzó tras el fallecimiento de su esposo en 1641, y culminó con su muerte en 1684 (Figura 3) -para luego continuar sus herederos-, en cuyo lapso contó con la colaboración de diferentes tipógrafos, como Pedro Quiñones, Diego Gutiérrez o su propio mayorazgo. A pesar de esto, en 1696 (doce años posteriores a su muerte) apareció una edición de la Cartilla de la doctrina religiosa en la que se indica que fue impresa "por la Viuda de Bernardo Calderón. Y por fu Original en la Imprenta de Juan Jofeph Guillena Carrafcofo". Benavides ya había impreso esta misma obra del jesuita Antonio Núñez de Miranda en 1680, en su propia imprenta, pues la familia gozaba de la concesión de impresión de las cartillas ${ }^{24}$, prebenda que se mantuvo gracias a que Antonio y Diego Calderón Benavides ejercieron el cargo de comisarios del Santo Oficio (como lo aprovechara también Henrico Martínez en su dignidad de cosmógrafo real ${ }^{25}$. Posiblemente, los herederos de la viuda de Calderón recurrieron al taller de Guillena en el Empedradillo (junto a su tienda), dado que la imprenta familiar, ubicada en la Calle de San Agustín, estaba ocupada imprimiendo los Exercicios espirituales de San Ignacio, del mismo Nuñez (con la indicación "por los Herederos de la Viuda de Bernardo Calderón"). Huelga decir que este autor, un prolífico orador mexicano, fungió como confesor espiritual de la poetisa jerónima Sor Juana Inés de la Cruz.

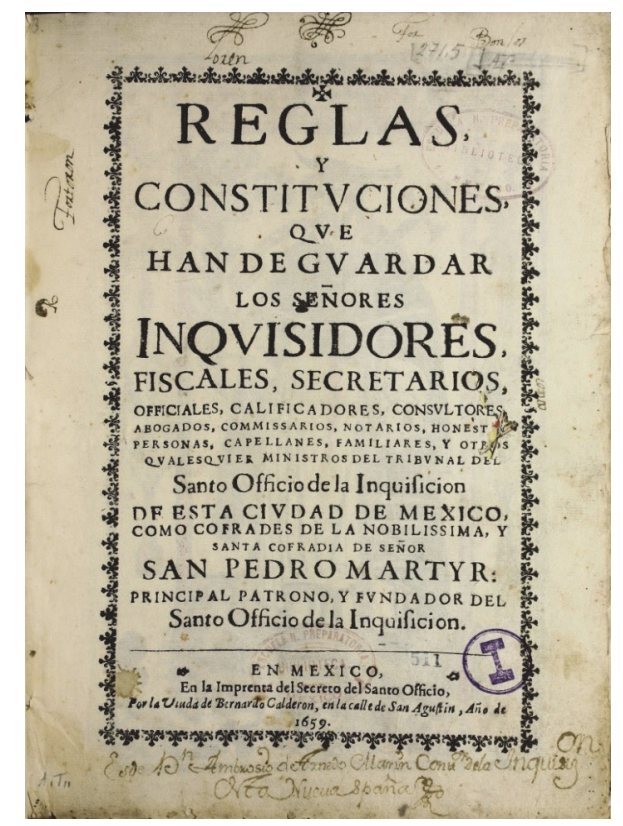

Figura 3. Portada de las Reglas y constitvciones que han de gvardar los señores inquisidores, de la Cofradía de San Pedro Mártir, impresas por Paula Benavides en 1659, en su Imprenta del Secreto del Santo Oficio ${ }^{26}$.

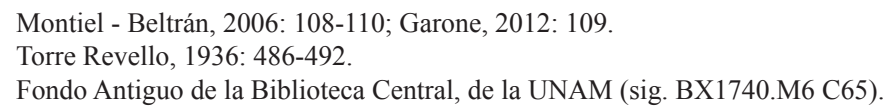


Como lo asentó Idalia García, aunque "la nómina de impresores aumentó considerablemente [...] no se puede negar lo interesante que resulta observar el escaso interés histórico que han generado estas personas del siglo XVII, quizá el periodo menos trabajado, ya que exceptuando a los Calderón [...] no encontramos otros textos dedicados específicamente a cada uno de estos talleres, a su producción ni a recuperar la historia de quienes ahí trabajaron"27. Si bien hubo muchos nombres, varios de estos impresores trabajaron por un breve plazo, por lo que su repertorio es sumamente reducido. Algunas imprentas terminaron su periodo de licencia en la capital, pero se extendieron a otras ciudades del Virreinato, como fue el caso de Pue$\mathrm{bla}^{28}$. Prácticamente todos los impresores que se presentan aquí guardan una relación entre sí.

En este sentido, el primer cuadro de la Ciudad de México se constituía como el epicentro de la cultura libresca, entramada por la presencia de las imprentas, las librerías, las bibliotecas y los colegios, y sus intrincadas relaciones (ya fueran familiares, laborales, comerciales o de vecindad). En algunos casos estos cuatro aspectos están íntimamente relacionados, y esto no resulta extraño ya que aquellos impresores que deseaban instaurar una tienda de libros, además de su taller, tenían que "dar fianza previamente", y el fiador, por lo general, se trataba de "un maestro conocido o compadre del pretendiente; o bien, un comerciante del barrio adonde tenía establecido su negocio" 29 . Por ejemplo, la familia Ribera -instaurados en la Plazuela del Empedradillo- constituyen un interesante entramado de relaciones familiares (de inicio, con Diego de Ribera y sus hijos, Hipólito y Juan de Ribera), aunque también de vínculos comerciales y de cercanía espacial. Es posible que fuera ahí donde Juan de Ribera conociera a su futura esposa, la hija de Bernardo de Calderón y Paula de Benavides, pues su padre, Diego de Ribera también poseía un local de venta en ese lugar. Al contraer nupcias, los hijos del patriarca de los Caderón alternaron los dos talleres, el emplazado a un costado de la Catedral y aquel ubicado en la calle de San Agustín. Además, dado que tres hijos de Calderón (Antonio, Diego y Bernardo) eran de la Orden de Frailes Menores, algunos de sus principales clientes eran justamente las bibliotecas franciscanas aledañas (como el Colegio Apostólico de San Fernando, el de San Diego o la del Convento Grande de San Francisco). De igual forma, puesto que su hijo Gabriel fue de la Orden de San Agustín, y dado que el taller era adyacente al convento de los agustinos, éstos fueron asiduos peticionarios suyos. Pero su alcance fue mucho más allá, ya que las obras que imprimieron pueden ser localizadas en otras bibliotecas (a partir de las marcas de propiedad), como la de Santo Domingo o la Casa Profesa.

A pesar de que en el siglo anterior se sentaron prolíficas bases en materia de edición, el ejercicio de imprimir no era todavía una tarea sencilla ni fácil a principios del XVII (ya sea para la obtención de una licencia como por la escasez y costo de los materiales de manufactura o la misma imprenta). Para ejemplificar esto, se puede mencionar el caso del flamenco Cornelio Adriano César (Cornelius Hadrianus Caesar), llegado a la Nueva España en 1595. Durante esta época, adquirir una prensa significaba traerla casi siempre de España a costos muy altos, tanto por el precio en sí de la máquina y de los distintos accesorios e insumos, como por los gastos de

\footnotetext{
García, 2015: 111-112.

Torre Revello, 1991: 148.

Carrera, 1954: 56.
} 
su transportación hasta América. Incluso, los materiales que podían conseguirse en el Virreinato eran igualmente caros. Aunque es escasa la información que se tiene al respecto, se sabe por algunos testimonios que en 1597 Cornelio Adriano César, pagó mil pesos por una prensa, misma que pasó por varias manos hasta que cayó en poder del español Diego Fernández de León, tras 88 años, quien la adquirió por mil quinientos pesos ${ }^{30}$. José Quiñones arguyó: "la falta de papel hizo también que muchos impresos no lograran conservarse, y aunque ningún bibliógrafo entendido habla del número de ejemplares que se tiraban de cada obra, yo juzgo que estos no serían muchos" 31 .

Si bien la situación respecto a algunos insumos fue precaria, en algunos casos podría ser la explicación sobre algunos aspectos de desarrollo discordantes con Europa. En México, el uso de libros impresos encuadernados en pergamino se debió principalmente a que este material, durante el siglo XVI, proveía de las características físicas y mecánicas necesarias para la protección del cuerpo del libro ${ }^{32}$. No obstante, su uso excesivo en las encuadernaciones mexicanas responde a que era un material de fácil adquisición, a diferencia de los libros encuadernados en piel y con tapas de cartón o madera, que requerían de mayor tiempo para su elaboración en comparación con aquellos en pergamino flojo que, por tanto, eran menos onerosos (véase más adelante las Figuras 12 y 13). Sin embargo, para el caso de la Ciudad de México, en vez de abaratarse, el negocio de la impresión se hizo más dispendioso con el paso del tiempo. Para el siglo XVIII una prensa podía costar entre cuatro mil y quince mil pesos de aquel entonces, de acuerdo a su calidad por supuesto ${ }^{33}$.

Sobre esto, existen historias dignas de mencionarse. Aquella prensa que Cornelio Adriano César había adquirido por mil pesos -luego de montársele un proceso inquisitorial por luteranismo- ${ }^{34}$, fue entregada a Henrico Martínez (Heinrich Martin), quien aducía ser alemán, y que fuera intérprete del Santo Oficio de las lenguas alemana y flamenca. Esta imprenta, junto con otros materiales comprados a Martín Montes de Oca, pasaría de Henrico Martínez a su hijo, el astrónomo Juan Ruiz (que había sido cajista de Diego López Dávalos), y sus herederos, y vendida después a Diego Fernández de León, quien la envió, junto con las mismas fuentes tipográficas y ornamentos que utilizó Martínez, hacia Oaxaca con la intención de instalar un taller en esa ciudad. Fernández de León empoderó como encargado para dicha imprenta al capitán Antonio Díaz Maceda (Fundador del Hospital y Convento de San Juan de Dios en Oaxaca), amigo del militar español Luis Ramírez de Aguilar, esposo finado de la futura licenciataria y primera impresora de Oaxaca, Francisca Flores ${ }^{35}$. Se constatan, pues, las relaciones diversas que envuelven a aquella imprenta incautada a Cornelio Adriano César.

Este cajista flamenco - otrora aprendiz en la imprenta dirigida por el maestro impresor y librero Christoffel Plantijn- ${ }^{36}$ pasó su condena recluido en el Colegio Real de la Santa Cruz de Tlatelolco, de 1600 a 1604 (custodiado en parte por fray Juan Bautista). En ese lugar estuvo trabajando con los herederos de Ocharte y con

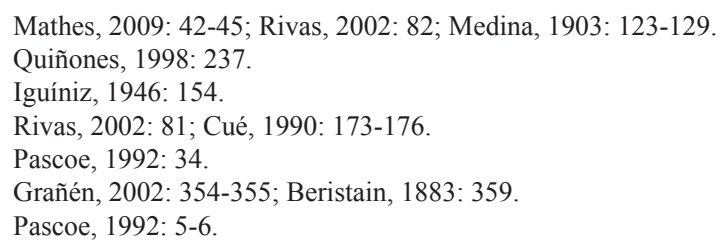


Diego López Dávalos, uno de los primeros punzonistas en figurar en este siglo. Fungió también como operario de la imprenta de Jerónimo Balli (1609-1610) y su madre (1614), quienes habían rentado la imprenta que perteneciera a Antonio de Espinosa (cuya hija era esposa de Diego López Dávalos). Un año después, trabajó con la viuda de López Dávalos y Diego Garrido (quien adquirió la prensa de ésta), y con Juan Blanco de Alcázar (1620), y pasados algunos años con Bernardo Calderón (1632-1633). Con los franciscanos, enseñó -con mucha renuencia- el oficio de impresor a los indígenas de las zonas aledañas al barrio de Tlatelolco ${ }^{37}$, quienes también aprendían otros oficios como la zapatería, la sastrería o la pintura ${ }^{38}$, ya que podían ser "oficiales de artes menores como carpinteros, albañiles, canteros, etcétera, y vivían de los jornales que los españoles y criollos adinerados pagaban por estos trabajos") $)^{39}$. Su periodo de reclusión sirve para proseguir con la idea de lo abigarrado que era producir libros. La historiadora Emma Rivas Mata determinó que aquellos años: "los pasó trabajando en el convento de Tlatelolco, donde recibía malos tratos y un miserable sueldo de 100 pesos al año, siendo que él valoraba su trabajo en 4 pesos diarios. Como es claro, el importe de su salario no fue suficiente para recuperar su prensa" 40 .

Otro de los oficiales de imprenta de Diego Garrido, además de Cornelio Adriano César, fue Pedro Gutiérrez - progenitor de Diego Gutiérrez-, quien le ayudó a imprimir las dos únicas obras que se conservan de su taller (Iesvs Maria: Sermon predicado por el mvy reverendo padre fray Antonio Gutierrez de la Sagrada Orden de los Predicadores, de 1621, y el Sermon que predico el illvstrissimo señor Doctor don Ivan de la Cerna, Arzobispo de Mexico, del consejo de su Magestad, de Juan de la Cerna, del mismo año). La falta de registros sobre los tirajes, ha hecho que sea difícil aún hoy contar con suficiente información sobre algunos impresores, sobre todo los considerados menores, como ocurre con Martín de Pastrana, del que poco se conoce. Sobre su trabajo se sabe que imprimió la Dispvtatio celebris, ac singvlaris, circa fidei profeffionem, et juramentum fidelitatis ab epifcopo tranflato per procuratorem proeftandum del entonces Arzobispo de Guatemala, Juan Zapata y Sandoval, un agustino mexicano, quien fuera catedrático de teología por algún tiempo en la Real y Pontificia Universidad de México y uno de los precursores del pensamiento criollo autonomista ("como mexicano que eres, pues estás oyendo a un mexicano $\mathrm{y}$, desde tu trono y desde el altísimo y seguro refugio de tu propia y querida patria, estás viendo a uno que lucha por ti" ${ }^{\prime 41}$ ). Es posible que Pastrana fuera un estudiante y operario temporal de la imprenta de Juan Blanco de Alcázar, quien de igual modo era egresado de la Universidad, y que se conoce firmaba como Bachalaureum Ioannem de Alcazar ("Bachiller Juan de Alcázar"). Al igual que otros, Alcázar tuvo algunos problemas con el Santo Oficio (como los tuviera Cornelio Adriano César, uno de sus primeros operarios), lo que explica en parte que dejara el oficio de impresor por veinte años, hasta que se instaló en Puebla en 1646, junto con una tienda libros (pese a haber trabajado para la Audiencia Real en 1619) ${ }^{42}$. Con excepción de Francisco

Ibídem: 7-11.

Carrera, 1954: 249.

Flores, 1970: 2.

Rivas, 2002: 82.

Zapata, 2004: 59.

Pago de la Cámara del Secreto de la Inquisición al Bachiller Juan Blanco por los edictos que imprimió. México, 11-IV-1618. AGNM, Inquisición, leg. 1516, exp. 59, f. 1r. 
Robledo, que se mudó a Puebla motivado por el obispo Juan de Palafox (a quien le publicó varias obras), muchos de los impresores de esta época se trasladaron avizorando un gran mercado en la ciudad de Puebla ${ }^{43}$.

Otro caso emblemático es el de uno de los descendientes de la dinastía Ocharte, conocido como Pedro de Charté. De su legado sólo se conoce una obra que fue impresa en 1630: la Relación breve de la admirable y milagrosa vida de algunos religiosos de la Orden de Santo Domingo, de la provincia de Guajaca, del provincial fray Jerónimo Moreno (a quien también le imprimiera Francisco de Salvago), y que tuvo por un tiempo como oficial de prensa a Bartholomé de Gama, otro impresor del que se salvaguarda sólo una obra (La estrella del Occidente, la Rosa de Lima, autoría del dominico Pedro del Castillo, impresa en 1670), con ayuda de la prensa de su entonces patrón, Francisco Rodríguez Lupercio.

Es del todo verosímil pensar que Charté se tratara de uno de los hijos menores que Pedro Ocharte tuvo con María de Sançoric, nacido alrededor de 1572, y que fue llamado como él ${ }^{44}$. También es admisible creer que haya sido sólo un pariente, pues se sabe que Pedro de Charté también era francés (de la misma región, Rouen), y que fue requerido por el tribunal de la Inquisición al ser acusado de difundir la doctrina luterana (con el consiguiente confisco de sus bienes y una multa de dos mil pesos), y que Diego de Sançoric - cuñado de Pedro Ocharte- fuera su fiador ${ }^{45}$. Es muy posible que esta situación sea la razón del precario conocimiento de su trabajo como impresor, al verse truncado a raíz de sus embrollos con las autoridades de la Inquisición. Estos problemas también los tuvo su pariente Ocharte, quien -junto con su fundidor de tipos, el andaluz Juan Ortiz- también recibió ayuda de este Diego de Sançoric durante su encarcelamiento ${ }^{46}$.

Como puede entreverse, no sólo la precariedad de los materiales para imprimir, ni los costos para hacerlo fueron un obstáculo, pues la legislación (inquisitorial, aduanal o virreinal) fue otra de las limitantes para los impresores, sobre todo en la segunda mitad de este siglo. En 1669, los fiscales de la Inquisición Nicolás de las Infantas y Venegas y Juan de Ortega Montañés notificaron al rey sobre las inconsistencias en la impresión de una obra que compuso el oidor Audiencia de México, Juan Francisco de Montemayor y Córdova de Cuenca, intitulada Excvbationes semicentvm ex decisionibvs Regice Chancellarice Sancti Dominici (acompañada de un apéndice llamado Propvgnatio pro regia ivrisditione et autoritate in cvivsdam clericis seditiose cavsa). Como todas las obras sobre temas eclesiásticos, ésta se sometió a un juicioso escrutinio, y el encargado para ello fue el franciscano Nicolás del Puerto, catedrático de la Universidad y provisor ordinario del tribunal del Santo Oficio. La situación que se suscitó fue que la versión que se examinó de este apéndice difería de la versión final que se imprimió en 1667, en el taller de Francisco Rodríguez Lupercio. Los fiscales reportaron que se intentó conseguir, infructuosamente, cada uno de los ejemplares en la ciudad, en librerías y bibliotecas, para someterlos a la respectiva censura, pero su tiraje fue tan escaso que no consiguieron uno solo ${ }^{47}$. Los impresores que de igual forma laboraban como mercaderes se veían expuestos con frecuencia a la revisión

\footnotetext{
43 Torre Villar, 2009: 146-148.

44 Medina, 1989: 411.

45 Ibídem: 402-406 y 426-427.

46 Araujo, 1979: 53.

47 Reyes, 2000: 882-883.
} 
y retención de las obras que transportaban en cajones arpillados, como le ocurrió a Diego Fernández de León en $1670^{48}$.

\section{Ubicación física de cada uno de los talleres y casas de impresión}

A continuación, se consigna en la Tabla 1 la ubicación del taller de los más de treinta impresores que hubo en la capital novohispana entre 1600 y 1699, a partir de algunos testimonios de procedencia. Cabe mencionar que en ciertos casos, ese domicilio coincidía con el local de una tienda de libros del mismo dueño, en otros casos, la librería se encontraba en otro sitio. Empero, la ubicación que aquí se asienta es la del lugar donde estaba emplazada la imprenta.

Tabla 1. Ubicación de los impresores en la Ciudad de México durante el siglo XVII.

\begin{tabular}{|c|l|l|}
\hline Núm. & \multicolumn{1}{|c|}{$\begin{array}{c}\text { Impresores } \\
\text { (periodo de actividad) }\end{array}$} & \multicolumn{1}{c|}{ Ubicación } \\
\hline $\mathbf{1}$ & $\begin{array}{l}\text { Henrico Martínez } \\
(1599-1611)\end{array}$ & $\begin{array}{l}\text { Plaza de Santo Domingo, junto al Palacio del Santo Oficio, } \\
\text { en el cual servía como intérprete }\end{array}$ \\
\hline $\mathbf{2}$ & $\begin{array}{l}\text { Melchor Ocharte Sansores } \\
(1599-1601)\end{array}$ & $\begin{array}{l}\text { Colegio Real de la Santa Cruz de Santiago Tlatelolco. } \\
\text { Heredó la imprenta de su madre, María de Sançoric, } \\
\text { segunda esposa de Pedro Ocharte }\end{array}$ \\
\hline $\mathbf{3}$ & $\begin{array}{l}\text { Luis Ocharte Figueroa } \\
(1600-1601)\end{array}$ & $\begin{array}{l}\text { Colegio Real de la Santa Cruz de Santiago Tlatelolco } \\
\text { 51. }\end{array}$ \\
\hline $\mathbf{4}$ & $\begin{array}{l}\text { Diego López Dávalos y su } \\
\text { viuda, María de Espinosa } \\
(1601-1615)\end{array}$ & $\begin{array}{l}\text { Colegio Real de la Santa Cruz de Santiago Tlatelolco } \\
\text { (25. }\end{array}$ \\
\hline $\mathbf{5}$ & $\begin{array}{l}\text { Cornelio Adriano César } \\
(1602-1633)\end{array}$ & $\begin{array}{l}\text { Sin un taller propio en este periodo, estuvo como cajista } \\
\text { en el Colegio Real de la Santa Cruz de Santiago Tlatelolco } \\
\text { (con los herederos de Ocharte, con López Dávalos y la } \\
\text { viuda de éste), en la Calle de San Agustín (con la familia } \\
\text { Balli y Bernardo Calderón), en la Calle de Tacuba (con } \\
\text { Diego Garrido) y en Santo Domingo (con Juan Blanco de } \\
\text { Alcázar) }\end{array}$ \\
\hline $\mathbf{6}$ & $\begin{array}{l}\text { Jerónimo Balli (1608-1610) } \\
\text { Junto al Convento de San Agustín, en la calle del mismo } \\
\text { nombre (hoy Calle República de Uruguay). Las bóvedas y } \\
\text { salas de este templo albergaron a la BNM de 1884 a 1978 }\end{array}$ \\
\hline
\end{tabular}

48 Revisión y retención de las obras que se transportaban en cajones del librero Diego Fernández de León. México, 1670. AGNM, Inquisición, leg. 1309, exp. 12, f. 137r.

49 Fernández, 1982: 522-523, 531-532.

50 Torre Villar, 2009: 145.

51 Zulaica, 1991: 247-249.

52 Torre Villar, 2009: 145.

53 Ibídem.

54 Medina, 1989: cxx-cxxi. 


\begin{tabular}{|c|c|c|}
\hline Núm. & $\begin{array}{c}\text { Impresores } \\
\text { (periodo de actividad) }\end{array}$ & Ubicación \\
\hline 7 & $\begin{array}{l}\text { Catalina del Valle, viuda de } \\
\text { Pedro Balli, y sus herederos } \\
(1611-1614)\end{array}$ & Contiguo al Convento de San Agustín ${ }^{55}$. \\
\hline 8 & Juan Ruiz (1613-1675) & $\begin{array}{l}\text { Plaza de Santo Domingo, cerca de la Calle del Relox (hoy } \\
\text { Calle República de Argentina) }\end{array}$ \\
\hline 9 & $\begin{array}{l}\text { Isabel de Quiroz, viuda de } \\
\text { Juan Ruiz, Feliciana Ruiz y } \\
\text { demás herederos } \\
(1675-1677)\end{array}$ & Plaza de Santo Domingo ${ }^{57}$. \\
\hline 10 & $\begin{array}{l}\text { Diego Garrido (1617-1627) } \\
\text { y su viuda, Ana de Herrera } \\
(1625-1628)\end{array}$ & $\begin{array}{l}\text { En la Calle Tacuba (que aún se lleva este nombre, } \\
\text { conjuntando los tramos entonces llamados Calle de San } \\
\text { Andrés y Calle de Santa Clara) }{ }^{58} \text {. }\end{array}$ \\
\hline 11 & $\begin{array}{l}\text { Juan Blanco de Alcázar } \\
(1620-1626)\end{array}$ & $\begin{array}{l}\text { Plaza de Santo Domingo, adyacente al edificio del tribunal } \\
\text { de la Inquisición (después Palacio de la Escuela de } \\
\text { Medicina) }{ }^{59} \text {. }\end{array}$ \\
\hline 12 & Pedro Gutiérrez (1620-1621) & En la Calle Tacuba ${ }^{60}$. \\
\hline 13 & $\begin{array}{l}\text { Diego Gutiérrez } \\
(1628-1643)\end{array}$ & En la Calle Tacuba ${ }^{61}$. \\
\hline 14 & Martín de Pastrana (1623) & $\begin{array}{l}\text { Es posible que su prensa estuviera vinculada a la } \\
\text { Universidad, entre la Calle de las Escalerillas y la Calle } \\
\text { del Colegio de San Yldefonso (actuales Calles República } \\
\text { de Guatemala y de San Ildefonso) o que fuera la misma de } \\
\text { Juan Blanco de Alcázar en Santo Domingo }{ }^{62} \text {. Entre estas } \\
\text { calles, se sitúa la Calle de Donceles, en la que actualmente } \\
\text { se pueden encontrar en los portones de las viejas casonas } \\
\text { varios locales de libreros. }\end{array}$ \\
\hline
\end{tabular}

55 Ibídem.

56 La ubicación de la imprenta de Juan Ruiz se determina por las fuentes que señalan que es la misma que adquirió Henrico Martínez, dispuesta en la Puerta de Santo Domingo, y que le perteneciera al flamenco Cornelio Adriano César. Francisco Pérez Salazar, señala que, pese a que en su acta de matrimonio Ruiz manifestó ser hijo del astrónomo Luis de Vargas y Juana Leonor, en su declaración testamentaria hizo asentar que era hijo legítimo de Martínez. Según lo dicho por Francisco de la Maza, esto "hace suponer lógicamente, mientras no se pruebe lo contrario, que pasó a su poder la imprenta de Enrico Martínez"; Maza, 1991: 28; Pérez, 1987: 177; Garone, 2012: 107-108.

57 Maza, 1991: 28.

58 Zahar, 2006: 18.

59 Rivas, 2002: 86; Medina, 1989: cxxiv.

60 Rivas, 2002: 86-87.

${ }^{61}$ Ibídem: 87; Medina, 1989: cxxvi.

62 Ibídem. 


\begin{tabular}{|c|c|c|}
\hline Núm. & $\begin{array}{l}\text { Impresores } \\
\text { (periodo de actividad) }\end{array}$ & Ubicación \\
\hline 15 & $\begin{array}{l}\text { Francisco Salvago } \\
(1629-1638)\end{array}$ & $\begin{array}{l}\text { Hasta 1630, tuvo su imprenta (operada por Pedro } \\
\text { Quiñones), y también librería, en la Portería de Santo } \\
\text { Domingo (hoy Calle República de Brasil), y pronto en } \\
\text { solitario la calle de San Francisco (actualmente Calle } \\
\text { Francisco I. Madero) }{ }^{63} \text {. En sus inicios estuvo en la llamada } \\
\text { "Calle de la Acequia" (hoy Calle Corregidora) - por donde } \\
\text { corría la Acequia Real-, frente al Colegio Mayor de Santa } \\
\text { María de Todos los Santos (cuyo tramo se llamaba Calle } \\
\text { del Colegio de Santos). }\end{array}$ \\
\hline 16 & Pedro de Charté (1630) & $\begin{array}{l}\text { No queda clara su ubicación, pese a ser pariente de la } \\
\text { familia Ocharte (ya que el taller de éstos pasó a manos de } \\
\text { Diego López Dávalos y su viuda, y, posteriormente, con } \\
\text { Diego Garrido) }{ }^{64} \text {. }\end{array}$ \\
\hline 17 & $\begin{array}{l}\text { Bernardo Calderón } \\
(1631-1641)\end{array}$ & $\begin{array}{l}\text { Calle de San Agustín (hoy Calle República de Uruguay). } \\
\text { También tenía una librería en el Empedradillo }{ }^{65} \text {. }\end{array}$ \\
\hline 18 & Pedro Quiñones (1631-1669) & $\begin{array}{l}\text { Calle de San Francisco (hoy Calle Francisco I. Madero), } \\
\text { frente a la Casa Profesa }{ }^{66} \text {. }\end{array}$ \\
\hline 19 & $\begin{array}{l}\text { Paula de Benavides, viuda } \\
\text { de Bernardo Calderón } \\
\text { (1641-1684) }\end{array}$ & En la Calle de San Agustín. \\
\hline 20 & $\begin{array}{l}\text { Antonio Calderón Benavides } \\
(1645-1649)\end{array}$ & En la Calle de San Agustín ${ }^{67}$. \\
\hline 21 & $\begin{array}{l}\text { Francisco Robledo } \\
(1640-1647)\end{array}$ & $\begin{array}{l}\text { Calle de San Francisco. Instaló tiempo después un taller en } \\
\text { Puebla en } 1643^{68} \text {. }\end{array}$ \\
\hline 22 & $\begin{array}{l}\text { Hipólito de Ribera } \\
(1648-1656)\end{array}$ & $\begin{array}{l}\text { Plazuela del Empedradillo, a un lado de la Catedral en la } \\
\text { calle del mismo nombre (hoy Calle Monte de Piedad). No } \\
\text { debe confundirse con la calle Monte Alegre (hoy Justo } \\
\text { Sierra, continuación de la Calle Donceles que conserva ese } \\
\text { nombre) ni la Calle Monte Pío (actualmente ampliación de } \\
\text { la Calle San Ildefonso) }{ }^{69} \text {. }\end{array}$ \\
\hline
\end{tabular}

63 Zahar, 2006: 18.

${ }^{64}$ Medina, 1989: cxxvii.

65 Martínez, 2002: 11-12

66 Comenzó con su propia prensa hasta 1637, en la calle de San Francisco. Antes de tenerla, y marcharse a Puebla (donde se piensa fue el introductor de la imprenta en 1640 o en 1642), fue tipógrafo de Paula de Benavides y de Francisco Salvago. Algunos autores suponen que pudo no ser él quien introdujera la imprenta en Puebla, sino Juan Blanco de Alcázar en 1942 y Francisco Robledo en 1643; Rivas, 2002: 87; Torre Villar, 2009: 146.

67 Medina, 1989: cxxxi-cxxxii; Ward, 2012.

68 Zahar, 2006: 19.

69 Martínez, 2002: 11-12; Zahar, 2006: 19. 


\begin{tabular}{|c|c|c|}
\hline Núm. & $\begin{array}{l}\text { Impresores } \\
\text { (periodo de actividad) }\end{array}$ & Ubicación \\
\hline 23 & $\begin{array}{l}\text { Francisco de Rodríguez } \\
\text { Lupercio (1658-1673) }\end{array}$ & $\begin{array}{l}\text { Tuvo un taller de impresión (en el que también grababa), } \\
\text { y una librería en sociedad con Agustín de Santiesteban y } \\
\text { Vértiz en la Calle Puente de Palacio, llamada luego Calle } \\
\text { del Seminario (actual paso entre la Avenida José María } \\
\text { Pino Suárez y la Calle República de Guatemala), frente al } \\
\text { Palacio del Arzobispado }{ }^{70} \text {. }\end{array}$ \\
\hline 24 & $\begin{array}{l}\text { Jerónima Delgado, viuda } \\
\text { de Francisco Rodríguez } \\
\text { Lupercio, y sus herederos } \\
(1683-1699)\end{array}$ & $\begin{array}{l}\text { Calle Puente de Palacio }{ }^{71} \text {. Al morir en } 1697 \text {, sus herederos } \\
\text { continuaron imprimiendo hasta bien entrado el siglo XVIII, } \\
\text { pero aquí se considera sólo su periodo dentro del siglo XVII. }\end{array}$ \\
\hline 25 & $\begin{array}{l}\text { Agustín de Santiesteban y } \\
\text { Vértiz (1658-1661) }\end{array}$ & Calle Puente de Palacio ${ }^{72}$. \\
\hline 26 & Bartholomé de Gama (1670) & $\begin{array}{l}\text { No tuvo un taller propio, así que para editar su única obra } \\
\text { recurrió a la imprenta de la familia Rodríguez Lupercio }{ }^{73} \text {. }\end{array}$ \\
\hline 27 & $\begin{array}{l}\text { Miguel de Ribera, su viuda y } \\
\text { sus herederos (1675-1684) }\end{array}$ & Plazuela del Empedradillo ${ }^{74}$. \\
\hline 28 & Juan de Ribera (1677-1684) & Plazuela del Empedradillo ${ }^{75}$. \\
\hline 29 & $\begin{array}{l}\text { María de Benavides, viuda } \\
\text { de Juan de Ribera (hija de } \\
\text { Bernardo Calderón y Paula } \\
\text { de Benavides) (1684-1700) }\end{array}$ & Plazuela del Empedradillo y en la Calle de San Agustín ${ }^{76}$. \\
\hline 30 & $\begin{array}{l}\text { Herederos de la Viuda de } \\
\text { Bernardo Calderón } \\
(1684-1703)\end{array}$ & $\begin{array}{l}\text { Calle de San Agustín }{ }^{77} \text {. Dado que entablaron relaciones } \\
\text { comerciales con Juan Guillena Carrascoso para usar } \\
\text { su taller, también se considera esta locación en donde } \\
\text { imprimieron. }\end{array}$ \\
\hline 31 & $\begin{array}{l}\text { Juan José Guillena } \\
\text { Carrascoso (1684-1700) }\end{array}$ & $\begin{array}{l}\text { Plazuela del Empedradillo, junto a las casas del } \\
\text { marquesado. Ahí tuvo la tienda de libros y su taller de } \\
\text { imprenta }^{78} \text {. }\end{array}$ \\
\hline
\end{tabular}

70 El nombre de la Calle de Puente de Palacio (llamada así en el siglo XIX) hace referencia al hecho de que los puentes cruzaban las acequias. A partir de la obra del bachiller poblano Juan de Viera, presbítero del Arzobispado, se puede dilucidar el sitio del Puente del Palacio; Viera, 1992: 44; Zahar, 2006: 20; Martínez, 2002: 13.

71 Zahar, 2006: 20 .

72 Ibídem.

73 Medina, 1989: cxxxvii.

74 Posible descendiente de Diego de Ribera. No debe confundirse con el hijo de Juan de Ribera, Miguel de Ribera Calderón, impresor en el siglo XVIII; Ibídem; Martínez, 2002: 11-12.

75 Ibídem; Zahar, 2006: 20.

76 Martínez, 2002: 12-13; Rivas, 2002: 93.

77 Martínez, 2002: 11-12.

78 Ibídem; Zahar, 2006: 21. 


\begin{tabular}{|c|c|l|}
\hline Núm. & \multicolumn{1}{|c|}{$\begin{array}{c}\text { Impresores } \\
\text { (periodo de actividad) }\end{array}$} & \multicolumn{1}{c|}{ Ubicación } \\
\hline 32 & $\begin{array}{l}\text { Diego Fernández de León } \\
(1690-1696)\end{array}$ & $\begin{array}{l}\text { Se instaló en la Casa Profesa, en la zona de la Calle de } \\
\text { San Francisco, gracias a un contrato con la prepositura de } \\
\text { dicho recinto, ocupado por la Compañía de Jesús. Volvería } \\
\text { a instalarse como impresor en la Ciudad de México hasta } \\
1710, \text { en el Portal de las Flores, año en que fallece y que le } \\
\text { sucede brevemente su viuda }\end{array}$ \\
\hline
\end{tabular}

De la tabla anterior, se puede dilucidar que la Ciudad de México no era tan grande en aquel entonces, ya que todas las imprentas se encontraban relativamente cerca entre sí, por lo que el clima cultural libresco estaba concentrado con mayor fuerza en las zonas aledañas a la Catedral. Lo que hoy conocemos como el cuadro central de la ciudad constituía, prácticamente, lo que era propiamente la ciudad, por lo que esto ayuda a determinar mejor las relaciones comerciales de los mercaderes y los medios de circulación de los libros. En la Figura 4, se podrá puede observar la traza urbana del cuadro central de la capital novohispana, a través del levantamiento del Plan General de la Ciudad de México, consignado por el teniente coronel Diego García Conde, en el año de 1793 (durante el proyecto de construcción del camino de la capital a Toluca) ${ }^{80}$, en el que se puede constatar que "la ciudad fue construida alrededor de una plaza central, en la que se encontraba la catedral, pero las calles, aunque rectas, no eran completamente paralelas [...] las calles situadas al este y al norte de la plaza central no guardan perfecta correspondencia" ${ }^{\prime 1}$.

Para el presente trabajo, se decidió emplear este mapa por ser uno de los más fieles en cuanto al crecimiento de la ciudad, pero además por ser un recurso versátil tanto para ubicar las calles de aquel entonces como para identificarlas en correspondencia con los asentamientos actuales. Además, "hasta la aparición del plano de García Conde, tanto los intentos renacentistas como los barrocos de planos de ciudades novohispanas, no representan una realidad concreta. Podrán fascinarnos en cuanto obras de arte particularmente apreciables, como documentos fantásticos o a lo sumo ingenuos, pero totalmente irrelevante en lo tocante a su validez intrínseca" ${ }^{\text {" } 2 \text {. Para }}$ identificar los talleres de impresión, se utilizaron siete zonas del cuadro primario de la capital: A) Calle de San Agustín (Figura 5), B) Calle de San Francisco (Figura 6), C) Palacio del Arzobispado (Figura 7), D) Plazuela del Empedradillo (Figura 8), E) Calle de Tacuba (Figura 9), F) Plaza de Santo Domingo (Figura 10) y G) el Barrio de Santiago Tlatelolco (Figura 11). Salvo el barrio de Tlatelolco, prácticamente, todas estas manzanas circundaban la Plaza Mayor y tenían una relación estrecha con los conventos y colegios lindantes.

\footnotetext{
79 Medina, 1991: xxi-xxviii.

80 Gasto que debe emplearse en la composición del camino que media desde México hasta Santa Fe, para poner el camino de Toluca transitable para ruedas. México, 1793. AGNM, Caminos y calzadas, leg. 13, exp. 8, fs. 146182 y exp. 16 , fs. $268-325$.

81 Borah, 1974: 77 y 79-80.

82 Maza-Ortiz, 2008: 27.
} 
Pese a estar un poco más apartado, la inclusión del barrio de Tlatelolco fue algo primordial, ya que en esta zona se localizaron a los primeros cuatro impresores del siglo XVII (en el primer Colegio de Filosofía del continente). Estos cuatro impresores trabajaron estrechamente con los franciscanos en ese lugar, sobre todo con fray Juan Bautista, para la edición de sus obras. Los Ocharte y Cornelio Adriano César entablaron relación con él desde Texcoco (a finales del siglo anterior), cuando éste dirigía la prefectura del conjunto conventual localizado ahí. Continuaron su vínculo con él cuando se trasladó para hacerse cargo del Colegio de Tlatelolco (luego, López Dávalos también imprimiría para él). La presencia de estas imprentas hizo que los acervos de la biblioteca superaran a los del complejo conventual de San Francisco el Grande, ya que el colegio no sólo se nutrió de libros europeos (sobre todo de valiosas y bellísimas ediciones de impresores flamencos) sino de impresos mexicanos $^{83}$.

Ya entrado el siglo XVII, de todas las bibliotecas de la Provincia del Santo Evangelio de los franciscanos "la más copiosa de todas era la de Tlatelolco -probablemente la que restaba del antiguo Colegio de Santa Cruz, ya desaparecido como centro de enseñanza superior para indígenas, y la del nuevo Colegio de San Buenaventura para estudiantes franciscanos, recién inaugurado- que poseía 920 obras, muchas de ellas en varios volúmenes: tres, cinco, siete, nueve y hasta doce. El inventario, muy escueto, ocupa los folios 17-26" "\$4. Aquí, el padre Gómez Canedo se refiere a los Inventarios de los conventos de la Provincia del Santo Evangelio: Memoria de todo lo que pertenece a la sacristía del Convento de San Francisco (que se encuentra en el Fondo Franciscano de la Biblioteca Nacional de Antropología e Historia "Dr. Eusebio Dávalos Hurtado"). De las obras mencionadas por él en este inventario, muchas fueron prensadas en Amberes, en la Officina Plantiniana, pero de igual modo se mencionan impresos novohispanos, como los dos tomos del Sermonario en lengua mexicana, de mencionado fray Juan Bautista, prensados por Diego López Dávalos en 1606 y 1607 (ésta es una de las dos obras que imprimió que se tienen a resguardo en la Biblioteca Nacional de México, además de la parte primera de La política de escriptvras, del escribano real gaditano Nicolás de Yrolo Calar, editada en 1605).

83 Mathes, 2009: 47-69.

84 Gómez, 1981-1982: 68-69. 


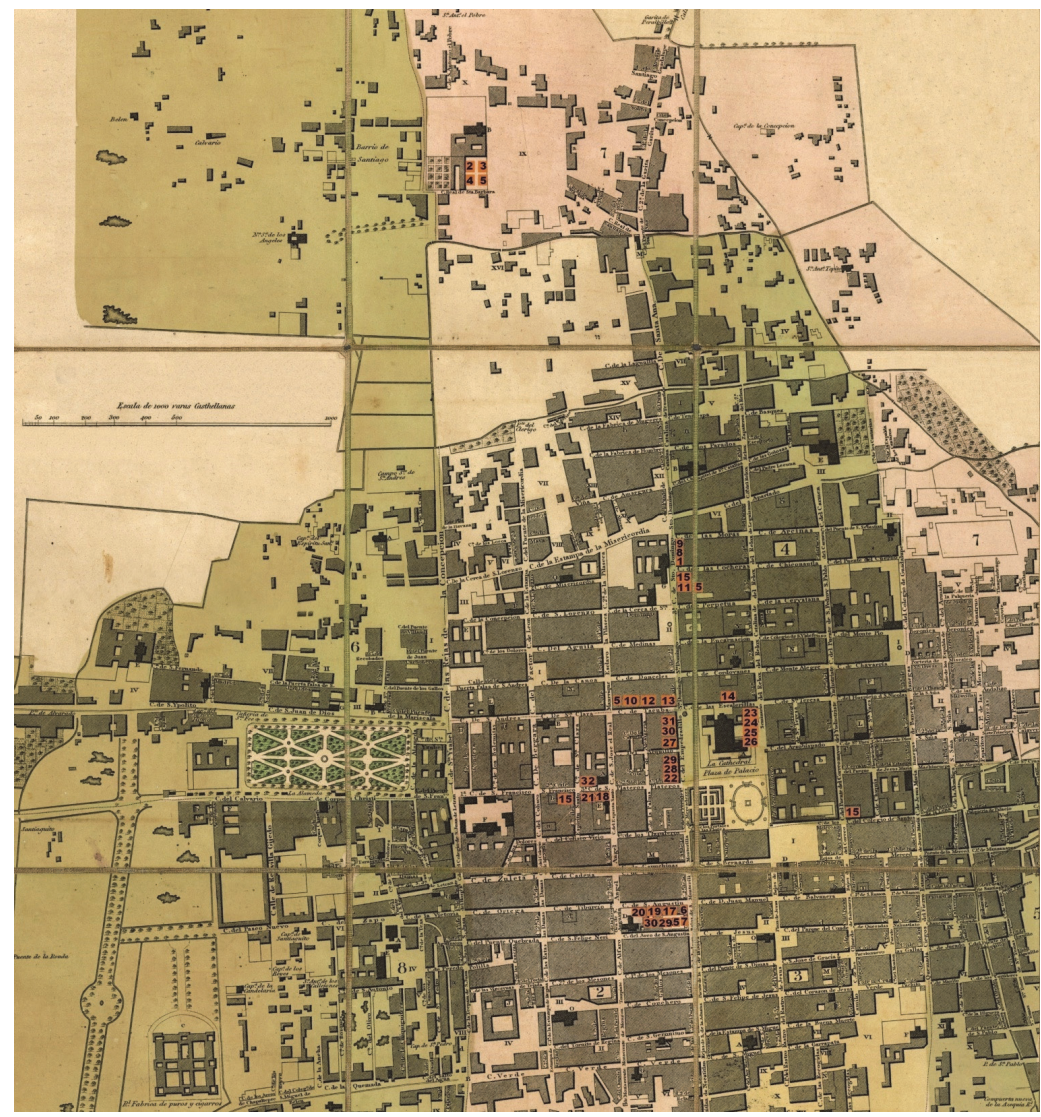

Figura 4. Detalle del Plan General de la Ciudad de México de 1793, pero grabado en 1807. Su versión más compacta fue realizada en Londres por el grabador y editor Edward Mogg, en 1811, célebre por sus guías de viajeros decimonónicas ${ }^{85}$.

Debe tenerse en mente que "la historia de la ciudad de México siempre estuvo relacionada, primero con la cruz de la espada de los conquistadores y después con la cruz de los religiosos que tomaron bajo 'su protección' a los súbditos de Su Majestad, naturales e indígenas, y a la misma ciudad" ${ }^{\prime \prime 6}$. Los conventos y colegios no sólo realizaban contratos con los impresores (como fue el caso de Diego Fernández de León en la Casa Profesa o los Ocharte y López Dávalos en Tlatelolco), asimismo, mantenían acuerdos con los mercaderes para instalarse en sus edificios o en las cercanías. Los dominicos, por ejemplo, permitieron a Pedro González instalarse en la Portería de Santo Domingo, y el cabildo catedralicio a Pedro Arias en la Puerta del Perdón. El obispo fray Juan de Zumárraga y los franciscanos no sólo trajeron la primera imprenta, sino que le permitieron a Andrés Martín instalar la primera tienda de libros en el edificio del Hospital Real del Amor de Dios.

85 Mapoteca "Manuel Orozco y Berra" del Servicio de Información Agroalimentaria y Pesquera, de la Secretaría de Agricultura, Ganadería, Desarrollo Rural, Pesca y Alimentación de México (sig. 926-OYB-725-A).

86 Araujo, 1979: 14. 
La ubicación que se presenta a continuación, en la Tabla 2, se ha hecho de acuerdo a las siete zonas mencionadas anteriormente, en fragmentos del mapa del Plan General de la Ciudad de México. Los números corresponden a los asignados a cada impresor en la Tabla 1. Para el caso de los impresores que también eran mercaderes, huelga insistir en que el número asignado para su ubicación sólo se refiere al sitio del taller de impresión y no al de su librería, salvo que ambos estuvieran en el mismo recinto.

Durante el siglo XVII, por datos que proporcionó el historiador y bibliógrafo chileno José Toribio Medina, se registra la cantidad de 1,824 impresos novohispanos, dispersos en los nombres de los treinta y dos casos de impresores establecidos en la Nueva España durante este periodo (pero no todos estos impresos se tienen conservados en las bibliotecas patrimonialistas de la actualidad, dada la rapiña y los continuos extravíos derivados de los traslados de las colecciones). Así como la imprenta de Cornelio Adriano César contó con una historia llena de personajes a través del periodo 1599-1720, muchos impresos que se han perdido, y que luego se han recuperado, también la tienen. Las marcas de procedencia son algunos de los elementos que han permito identificar parte de su travesía. Los elementos de la materialidad del libro no se abocan sólo a aquellos que atañen a sus dimensiones o a la tipografía (ya fueran letras capitulares, tipos móviles para títulos o para el resto del texto), sino de igual forma a otros elementos como las marcas de fuego, los ex libris o las encuadernaciones (Figuras 12, 13 y 14).

Tabla 2. Ubicación de cada impresor en el primer cuadro de la Ciudad de México.

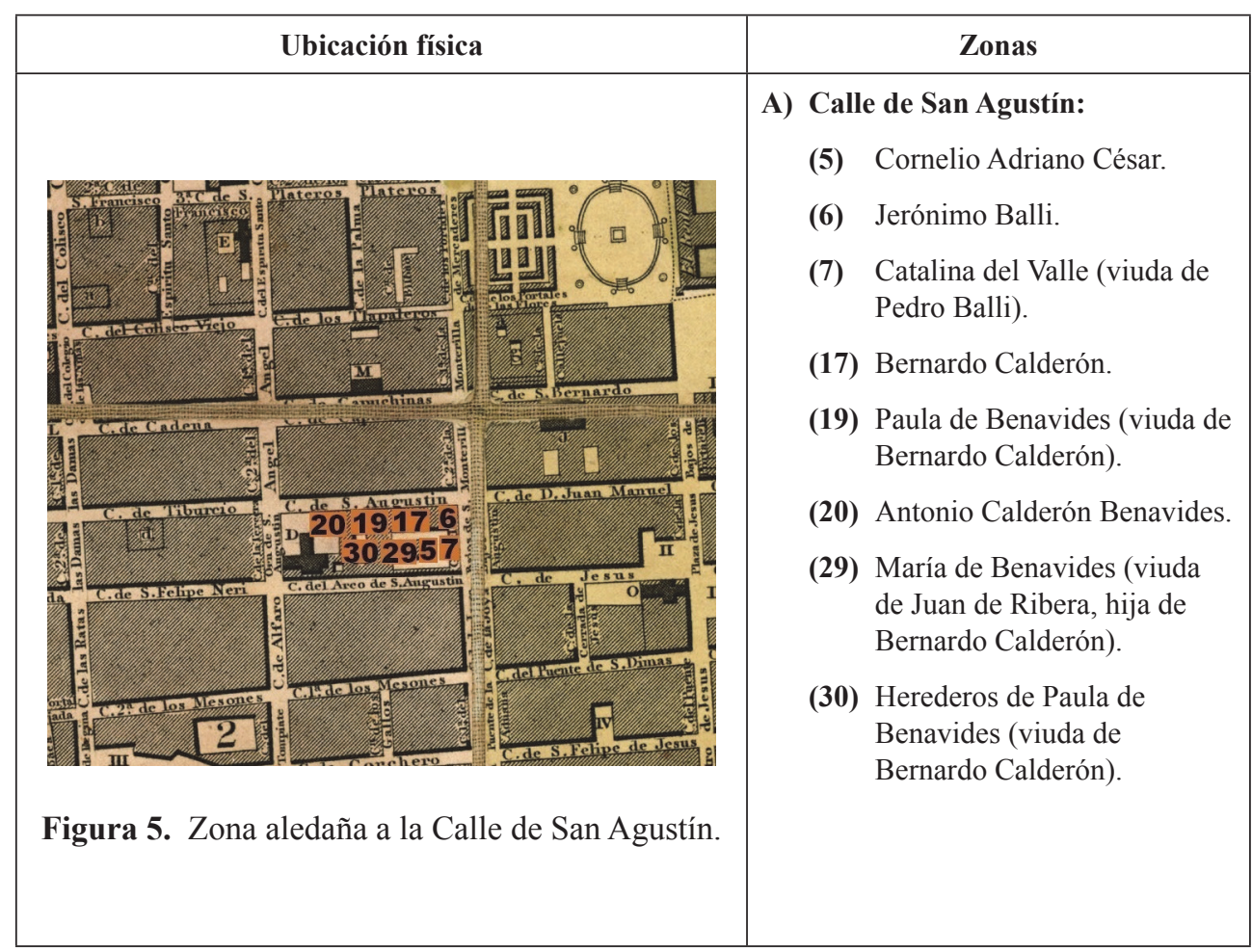




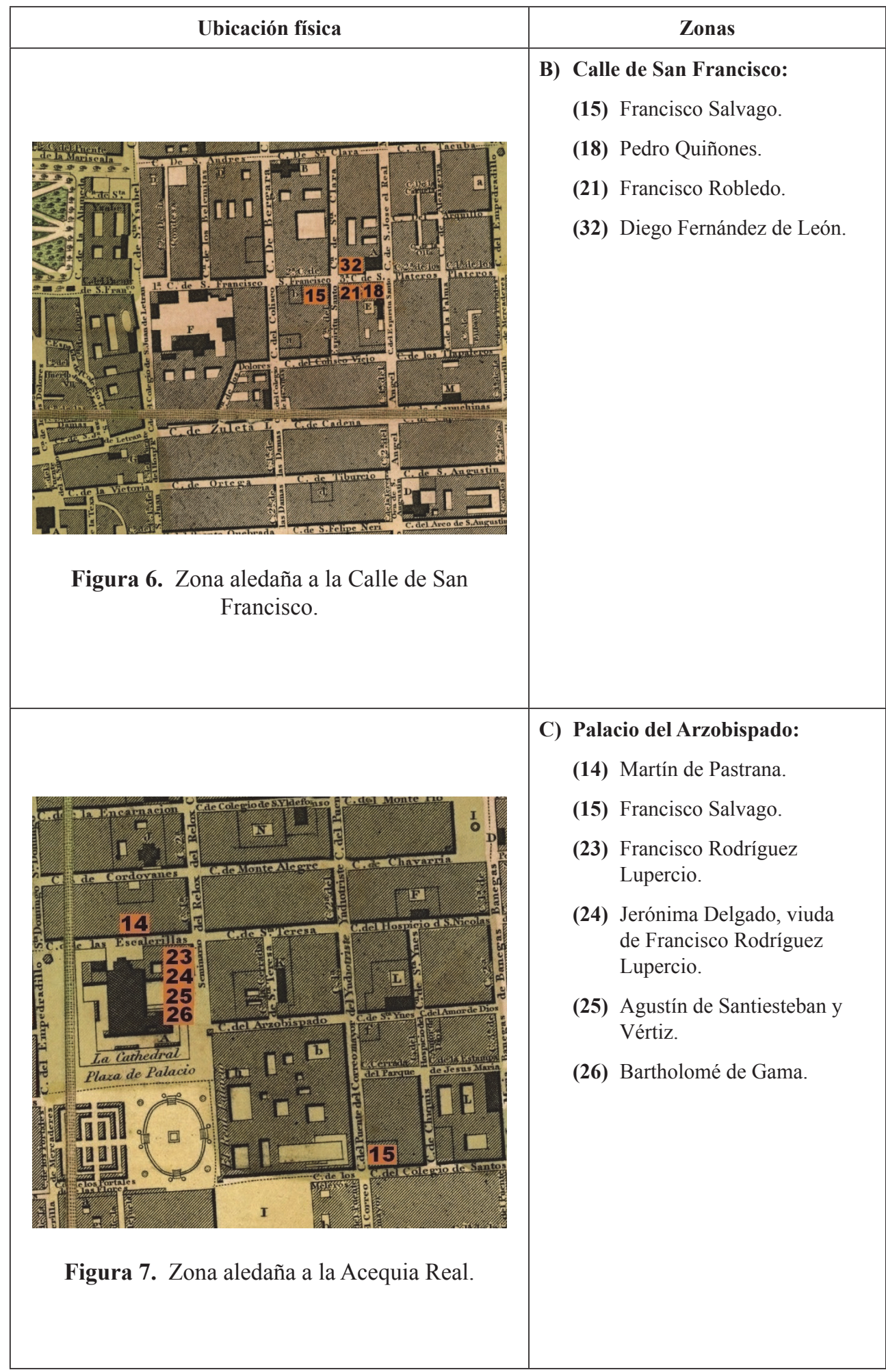




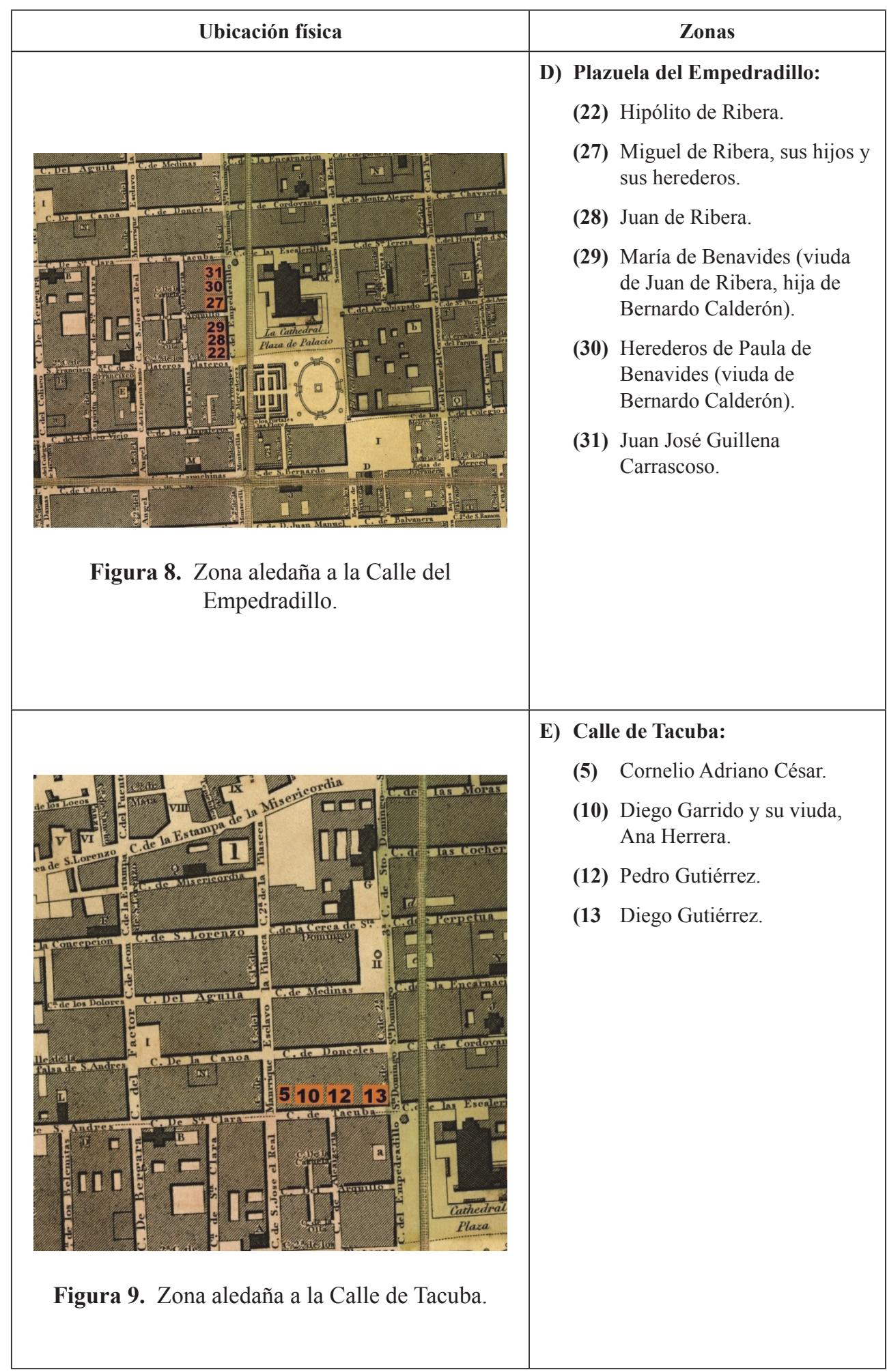




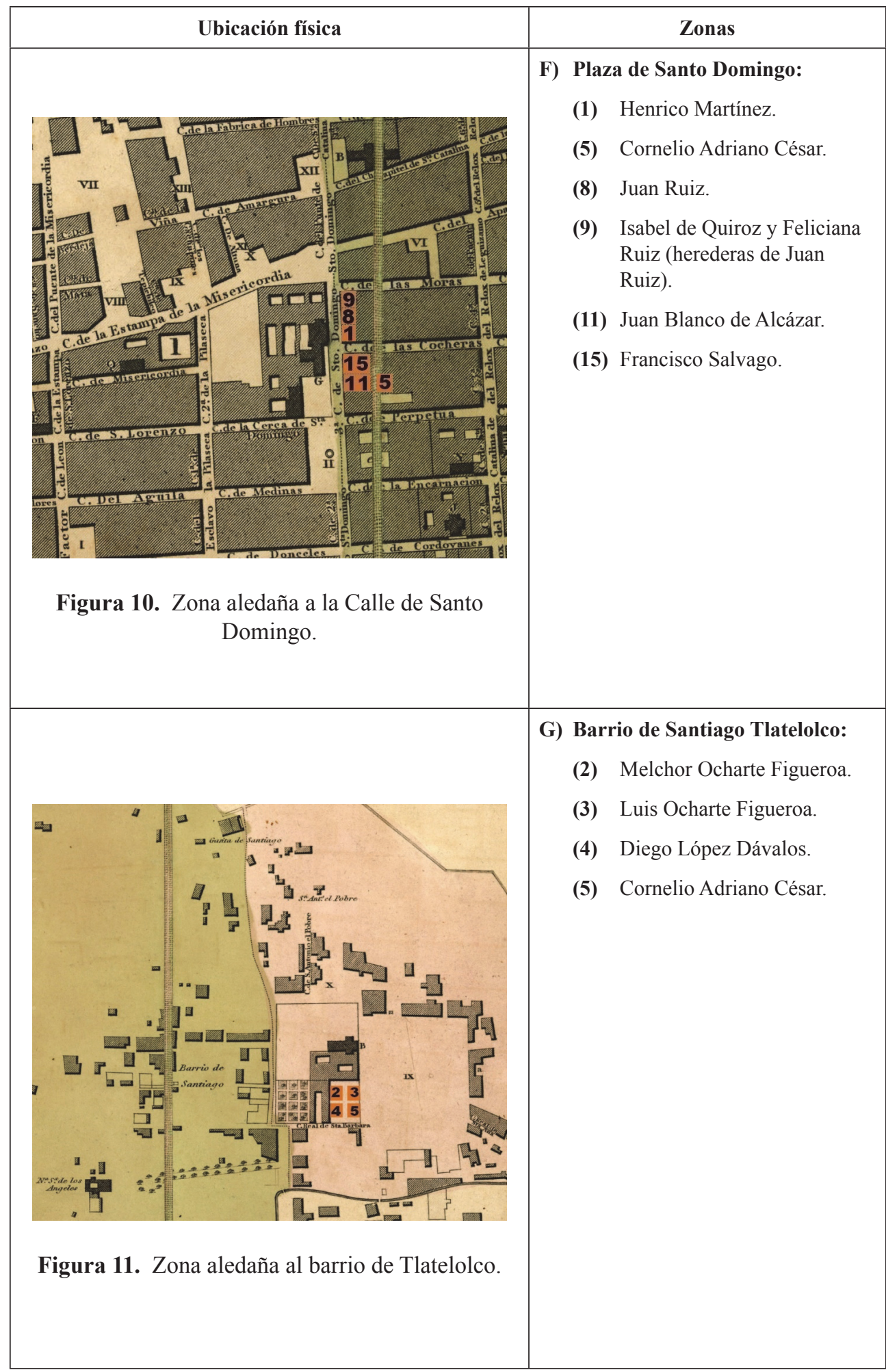



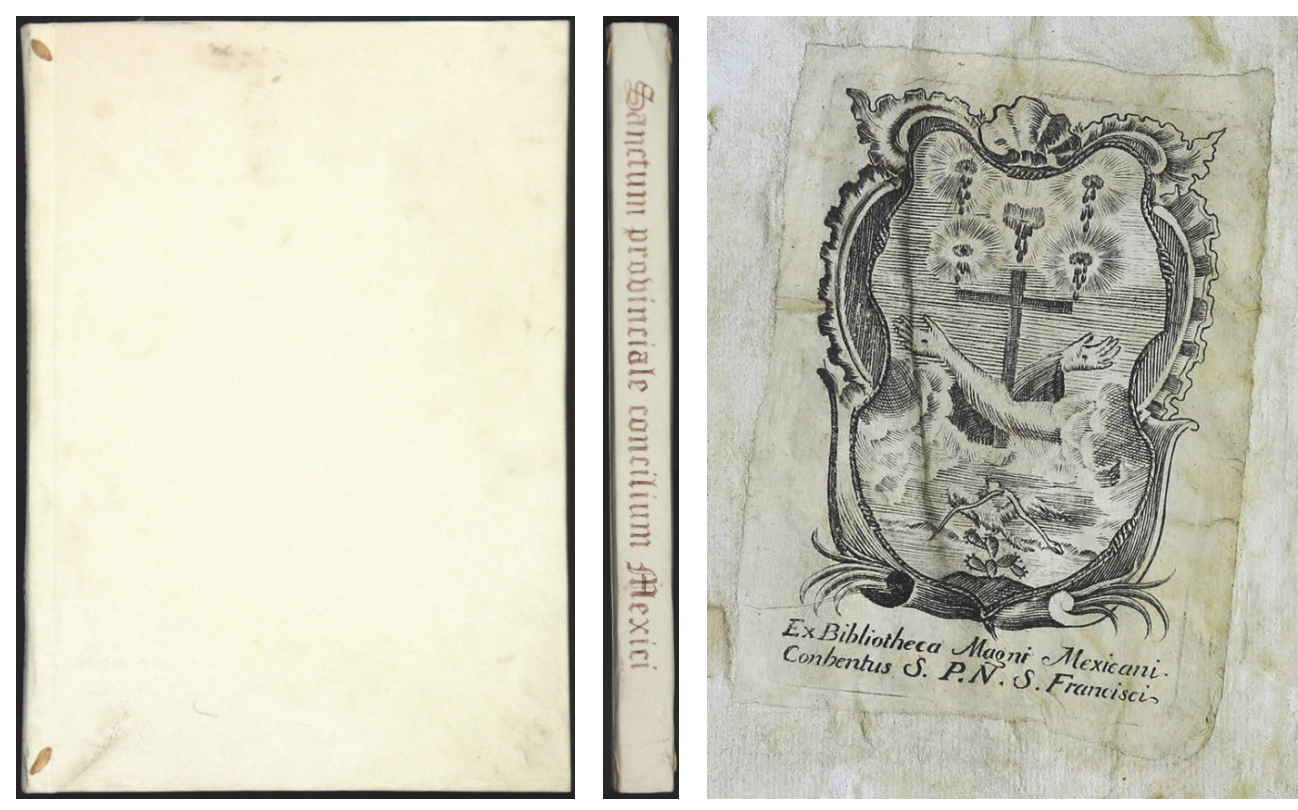

Figuras 12, 13 y 14. Encuadernación en pergamino flojo -la más utilizada en el siglo XVII en la Nueva España- de la cubierta del Sanctvm Provinciale Concilivm Mexici. En el reverso de la falsa portada se aprecia el ex libris en estampa del Convento Grande de San Francisco de México ${ }^{87}$.

Investigadores como Idalia García o Pedro Rueda Ramírez ${ }^{88}$ han hecho hincapié en los últimos años en diversos elementos de identificación hechas en los libros (anotaciones manuscritas, un sello, una etiqueta, una firma, una estampa o un membrete), las cuales contribuyen a revelar un poco más de la historia de las personas a quién perteneció el libro (o a quien actualmente pertenece) o de las bibliotecas en las que estuvo. A partir de estas marcas de propiedad se han logrado rastrear, por otro lado, algunas prácticas de lectura y estudio en algunas bibliotecas conventuales novohispanas, pero también las relaciones en el circuito comercial de libreros. Cada uno de estos elementos -algunos poco estudiados- posee latencia para realizar investigaciones minuciosas de una riqueza insospechada. El insigne historiador mexicano, Ernesto de la Torre Villar, refiriéndose a la variedad de formas que puede adoptar un ex libris, mencionó que "puede ser manuscrito o impreso en una cédula adherida, puede contener tan sólo el nombre del propietario o propietarios, pues también hay un ex libris de comunidades; puede contener un lema y un dibujo, generalmente grabado, que bien puede ser heráldico o bien tratarse de un dibujo artístico que exprese el gusto, la afición o la actividad que desarrolla el propietario" ${ }^{\$ 9}$. El ejemplar de la Figuras 12, 13 y 14 fue impreso en la casa de Juan Ruiz en 1622, que contaba con dos prensas con herencia de la tradición flamenca, y no sólo por los tipos y ornamentos

\footnotetext{
Fondo Antiguo de la Biblioteca Central, de la UNAM (sig. KBR975.I45).

García, 2010: 72-75; Rueda, 2016.

Torre Villar, 2000: 29.
} 
de su padre, y que a éste le traspasaron de los bienes confiscados a Cornelio Adriano César, sino por la predilección en el uso del gusto tipográfico de Amberes, como la incorporación de grabados calcográficos del ilustrador Samuel Van der Straet (Stradanus), como se muestra en esta portada arquitectónica (Figura 15).

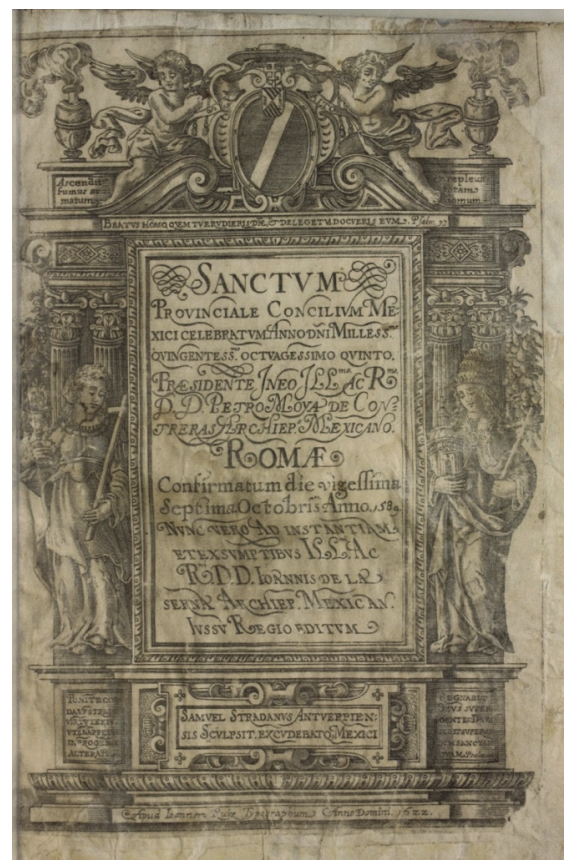

Figura 15. Portada arquitectónica (con capiteles alegóricos) del Sanctvm Provinciale Concilivm Mexici. En la parte baja de esta portada arquitectónica (en el estilóbato) se aprecia la leyenda que advierte que el autor del grabado es el ilustrador flamenco Samuel Van der Straet (Stradanus) ${ }^{90}$.

Juan Ruiz pertenece al grupo de impresores que heredó el negocio de alguno de los impresores del siglo XVI, sin que trascendiera realmente a más generaciones, a pesar de que el diseño de su trabajo es destacable (aunada su muerte con la fuerte competencia con la familia Calderón) ${ }^{91}$. Ruiz heredó a su nieta Feliciana no sólo la prensa, sino el oficio de imprimir, para que ésta lo reemplazara a su muerte, pero ella fenecería dos años después, por lo que su viuda se vio instada a expender la imprenta con los insumos, con algo de premura, a Diego Fernández de León -a través de la esposa de éste y familiar de Ruiz, Ángela Ruiz Machorro- ${ }^{92}$, que no era poca cosa sino "el arsenal completo y hasta sobrado de un impresor de aquellos lejanos tiempos"93.

90 Fondo Antiguo de la Biblioteca Central, de la UNAM (sig. KBR975.I45).

91 Licencia amplia para la viuda de Bernardo Calderón para imprimir toda clase de pequeños impresos destinados a la enseñanza de la lengua española y de pequeños catecismos. México, 1641. AGNM, General de Partes, leg. 8, exp. 176, f. 122.

92 Iguíniz, 1938: 20-21; Pérez, 1987: 177-180.

93 Pérez, 1924: 455. 
Es interesante agregar que tanto Ruiz como su padre se instituyen como impresores destacados que fueron, además, reconocidos autores en astronomía. En el caso de Henrico Martínez, son ya conocidas otras facetas suyas, como el ser cosmógrafo de Indias, intérprete en el tribunal del Santo Oficio de las lenguas flamenca y alemana, e ingeniero hidráulico de la ciudad (se encargaría del proyecto de desagüe de la Cuenca del Valle de México). Pero además, es el único autor conocido en todo el siglo XVII novohispano que imprimió sus propias obras, además de ser maestro impresor en los siglos XVI y XVII. Juan Ruiz, su hijo, también trabajó para el Santo Oficio, pero como impresor (concesión que también gozó brevemente Francisco Robledo).

\section{Conclusiones}

Este trabajo es un estudio liminar para conocer y explorar las prácticas culturales librescas que definieron el cuadro central de la Ciudad de México en el siglo XVII. Resulta muy notorio que los estudios realizados sobre impresos novohispanos, producidos en la centuria diecisietesca, se han focalizado sólo en ciertos talleres y determinados impresores (sobre todo, las familias más grandes que contaban con ciertas prebendas por parte de las autoridades). En consecuencia, un conjunto importante de los estos talleristas no han sido estudiados con el suficiente cuidado y aprecio, y por ende sus vínculos zonales, laborales, comerciales y familiares. Es por eso que hacerlo, con mayor o menor profundidad, se vuelve primordial para llamar la atención sobre un problema de sumo interés para la cultura del libro en este siglo.

Disiento sobre la designación que se ha hecho hacia este grupo específico de impresores signándolos como "menores". Si se tratara de la calidad, la gran mayoría de los impresos novohispanos serían inferiores comparados con los trabajos librescos europeos de la época, pero esto era de esperar dadas las trabas continuas para conseguir materias primas. Esta categoría de "impresores menores" es la que precisamente los ha relegado a un lugar "menor" o ignorado en el desarrollo de conocimiento sobre la cultura del libro en el periodo novohispano (por ejemplo, en algunos repertorios clásicos y recientes). Si bien, muchos de ellos no contaron con un taller propio o sólo se conoce una obra impresa, detrás de esto existen muchas situaciones que revelan la complejidad de la historia del libro. Las dimensiones del estudio del libro antiguo no se circunscriben sólo a su enfoque descriptivo material, sino a la historia y desarrollo del taller y del impresor, además de su contexto de producción. Los vericuetos a los que se enfrentaron estos impresores menores sacan a relucir algunas de las cuestiones más interesantes en la historia del libro mexicano, que expresan la complejidad de la realidad bibliográfica de esa época, en revesada por asuntos de índole jurídica, política y económica. Algunos de ellos se enfrentaron a insumos caros, a una competencia injusta con las familias más poderosas o a problemas con el Santo Oficio. Esto explica parte de su desaparición súbita, su cambio de giro o la mudanza a otras ciudades.

Una cuestión adicional que surge a partir de la existencia de estos impresores se centra sobre la posibilidad de imprimir aún sin contar con un taller propio, lo que atañe a las prerrogativas para un oficial de imprenta (cuando Carrera Stampa, habló de las obligaciones y derechos de los oficiales de los talleres, este privilegio se menciona). En síntesis, llamarlos "impresores menores" resulta ser sumamente reduccio- 
nista, ya que algunos de ellos fueron los introductores e impulsores de la imprenta en Puebla, como lo fueron Pedro Quiñones, Juan Blanco de Alcázar y Francisco Robledo (con un gran apoyo del obispo Palafox).

Si bien esta época es conocida por una presencia relevante de las mujeres impresoras - no sólo las viudas- debe señalarse que muchas de ellas lo hicieron a través de la regentía de uno de estos impresores, que sirvieron como oficiales y muchas de sus aportaciones en cuestión de diseño y uso de grabados es de destacar. La mano de Cornelio Adriano César puede notarse en varios de sus trabajos en los talleres de los Balli o Calderón, aunque no sea mencionado en la portada. Se debe considerar, igualmente, que otras de las características del siglo XVII, además de una mayor participación de las mujeres como cabeza de los talleres, es la correspondiente conformación de linajes familiares de impresores y la diversificación del negocio de la impresión a la venta de libros. A partir de esto, se dio la conformación de fabulosas bibliotecas, además de las colecciones formidables de los bibliófilos.

\section{Referencias bibliográficas}

Anderson Imbert, Enrique. Historia de la literatura hispanoamericana, I: La Colonia, cien años de república. México: Fondo de Cultura Económica, 1997.

Araujo, Eduardo F. Primeros impresores e impresos en Nueva España. México: Miguel Ángel Porrúa, 1979.

Balbuena, Bernardo de. Grandeza mexicana. México: Sociedad de Bibliófilos Mexicanos, 1927.

Barbosa Ramírez, A. René. Estructura económica de la Nueva España. México: Siglo Veintiuno, 1981.

Beristain de Souza, José Mariano. Biblioteca hispano americana setentrional, II. Amecameca: Tipografía del Colegio Católico, 1883.

Borah, Woodrow. "La influencia cultural europea en la creación de los centros urbanos hispanoamericanos". En Ensayos sobre el desarrollo urbano de México, Calnek, Edward et al. México: Secretaría de Educación Pública, 1974, 66-94.

Carreño, Elvia et al. El mundo en una sola mano: Bibliotecarios novohispanos. México: Apoyo al Desarrollo de Archivos y Bibliotecas de México, 2013.

Carrera Stampa, Manuel. Los gremios mexicanos: La organización gremial en Nueva España (1521-1861). México: Edición y Distribución Ibero Americana de Publicaciones, 1954.

Cué Cánovas, Agustín. Historia social y económica de México: 1521-1854. México: Trillas, 1990.

Febvre, Lucien - Martin, Henri-Jean. La aparición del libro. México: Fondo de Cultura Económica, 2005.

Fernández del Castillo, Francisco (comp.). Libros y libreros del siglo XVI. México: Fondo de Cultura Económica: Archivo General de la Nación, 1982.

Flores Olea, Aurora. "Los regidores de la Ciudad de México en la primera mitad del siglo XVII". Estudios de Historia Novohispana, vol. 3, n 3 (1970), 1-24.

García Aguilar, María Idalia. "Atrás de la escena tipográfica: Los impresores en la nueva España". Investigación Bibliotecológica: Archivonomía, Bibliotecología e Información, vol. 29, no 66 (2015), 105-137.

García Aguilar, María Idalia. "Posesión libresca: Elementos de procedencia novohispana en bibliotecas mexicanas". Letras Históricas, vol. 22, nº 3 (2010), 69-90. 
Garone Gravier, Marina. “¿Ornamentos tipográficos? Las mujeres en el mundo del libro antiguo: Algunas noticias biobibliográficas”. En Leer en tiempos de la Colonia, editado por García Aguilar, Idalia - Rueda Ramírez, Pedro. México: UNAM, Centro Universitario de Investigaciones Bibliotecológicas, 2010, 163-214.

Garone Gravier, Marina. La tipografía en México: Ensayos históricos (siglos XVI al XIX). México: UNAM, Escuela Nacional de Artes Plásticas, 2012.

Gómez Canedo, Lino. "Viejas bibliotecas de México: Un informe de 1662-1664”. Boletín del Instituto de Investigaciones Bibliográficas, $\mathrm{n}^{\text {os }}$ 18-19 (1981-1982), 67-73.

Grañén Porrúa, María Isabel. "Libros e imprenta en Oaxaca durante la época colonial”. En Del autor al lector: I: Historia del libro en México, II: Historia del libro, coordinado por Castañeda García, Carmen. México: Centro de Investigaciones y Estudios Superiores en Antropología Social, 2002, 345-358.

Iguíniz, Juan Bautista. La imprenta en la Nueva España. México: Porrúa, 1938.

Iguíniz, Juan Bautista. El libro: Epítome de bibliología. México: Porrúa, 1946.

Kant, Immanuel. Principios metafísicos del derecho. Madrid: Librería de Victoriano Suárez, 1873.

Leonard, Irving A. La época barroca en el México colonial. México. Fondo de Cultura Económica, 1976.

Martínez Leal, Luisa. "Los impresores libreros en Nueva España del siglo XVII". Casa del Tiempo, vol. 4, no 40 (2002), 9-14.

Mathes, W. Michael. "Los flamencos en las artes gráficas en Nueva España en los siglos XVI y XVII: Cornelio Adrián César, Enrico Martínez y Samuel Stradamus (van der Straet)". En Memorias e historias compartidas: Intercambios culturales, relaciones comerciales y diplomáticas entre México y los Países Bajos, siglos XVI-XX, coordinado por Pérez Rosales, Laura - Van der Sluis, Arjen. México: Universidad Iberoamericana, 2009, 41-69.

Maza, Francisco de la. Enrico Martínez: Cosmógrafo e impresor de Nueva España. México: México: UNAM, Instituto de Investigaciones Bibliográficas, 1991.

Maza, Francisco de la - Ortiz Macedo, Luis. Plano de la Ciudad de México de Pedro de Arrieta, 1737. México: UNAM, Instituto de Investigaciones Estéticas, 2008.

Medina, José Toribio. Historia del Tribunal del Santo Oficio de la Inquisición en México. Santiago de Chile: Imprenta Elzeviriana, 1903.

Medina, José Toribio. La imprenta en México: 1539-1821, I (1539-1600). México: UNAM, Dirección General de Publicaciones, 1989.

Medina, José Toribio. La imprenta en la Puebla de los Ángeles: 1640-1821. México: UNAM, Instituto de Investigaciones Bibliográficas, 1991.

Montiel Ontiveros, Ana Cecilia - Beltrán Cabrera, Luz del Carmen. "Paula de Benavides, impresora del siglo XVII: El inicio de un linaje". Contribuciones desde Coatepec: Revista de Humanidades, $\mathrm{n}^{\circ} 10$ (2006), 103-115.

Moreno Toscano, Alejandra. “Economía regional y urbanización: Tres ejemplos de relación entre ciudades y regiones en Nueva España a finales del siglo XVIII”. En Ensayos sobre el desarrollo urbano de México, Calnek, Edward et al. México: Secretaría de Educación Pública, 1974, 95-130.

Pascoe, Juan. Cornelio Adrián César: Impresor en la Nueva España (1597-1633). México: Redacta: Taller Martín Pescador, 1992.

Pérez Salazar, Francisco. Los impresores de Puebla en la época colonial: Dos familias de impresores mexicanos del siglo XVII. Puebla: Gobierno del Estado de Puebla, 1987.

Pérez Salazar, Francisco. "Dos familias de Impresores mexicanos del siglo XVII". Memorias de la Sociedad Cientifica “Antonio Alzate”, t. XLIII, n 9-12 (1924), 447-511. 
Pompa y Pompa, Antonio. 450 años de la imprenta tipográfica en México. México: Asociación Nacional de Libreros, 1988.

Quiñones Melgoza, José. "Sor Juana Inés de la Cruz desde la perspectiva de la cultura y la bibliografía novohispana”. En Novahispania, IV, Mauricio Beuchot et al. México: UNAM, Instituto de Investigaciones Filológicas, 1998, 229-244.

Reyes Gómez, Fermín de los. El libro en España y América: Legislación y censura (siglos XV-XVIII), II. Madrid: Arco/Libros, 2000.

Ricœur, Paul. La memoria, la historia, el olvido. México: Fondo de Cultura Económica, 2004.

Rivas Mata, Emma. "Impresores y mercaderes de libros en la Ciudad de México (siglo XVII)". En Del autor al lector: I: Historia del libro en México, II: Historia del libro, coordinado por Castañeda García, Carmen. México: Centro de Investigaciones y Estudios Superiores en Antropología Social, 2002, 71-102.

Rueda Ramírez, Pedro. "Los estudios de la procedencia de los libros: Las marcas personales". En Jornada de Ex Libris y Coleccionismo (8 de junio), Facultat de Biblioteconomia i Documentació, Universitat de Barcelona, Catalunya, 2016.

Sigüenza y Góngora, Carlos de. Libra astronómica y filosófica. México: UNAM, Centro de Estudios Filosóficos, 1959.

Torre Revello, José. El libro, la imprenta y el periodismo en América durante la dominación española. México: UNAM, Instituto de Investigaciones Bibliográficas, 1991.

Torre Revello, José. "Licencias para impresión de libros". En Boletín del Archivo General de la Nación, t. VII, n 4, (1936), pp. 481-493.

Torre Villar, Ernesto de la. "Época colonial: Siglos XVI y XVII". En Historia documental de México, I, León-Portilla, Miguel et al. México: UNAM, Instituto de Investigaciones Históricas, 1974, 161-320.

Torre Villar, Ernesto de la. Ex libris y marcas de fuego. México: UNAM, Dirección General de Publicaciones y Fomento Editorial, 2000.

Torre Villar, Ernesto de la. Breve historia del libro en México. México: UNAM, Dirección General de Publicaciones y Fomento Editorial, 2009.

Viera, Juan de. Breve y compendiosa narración de la Ciudad de México. México: Instituto Dr. José María Luis Mora, 1972.

Ward, Kenneth C. "Conjeturas sobre los orígenes de la imprenta en Puebla". En Miradas a la cultura del libro en Puebla: Bibliotecas, tipógrafos, grabadores, libreros y ediciones en la época colonial, editado por Garone Gravier, Marina. México: Benemérita Universidad Autónoma de Puebla: UNAM, Instituto de Investigaciones Bibliográficas, 2012, 161-204.

Zahar Vergara, Juana. Historia de las librerías de la Ciudad de México: Evocación y presencia. México: UNAM, Centro Universitario de Investigaciones Bibliotecológicas, 2006.

Zapata y Sandoval, Juan. De iustitia distributiva et acceptione personarum ei opposita disceptatio. Madrid: Consejo Superior de Investigaciones Científicas, 2004.

Zulaica Gárate, Román. Los franciscanos y la imprenta en México en el siglo XVI. México: UNAM, Instituto de Investigaciones Bibliográficas, 1991. 